\title{
REVIEW
}

\section{The epigenetic and transcriptional landscape of neuroendocrine prostate cancer}

\author{
Alastair Davies',2, Amina Zoubeidi1,2 and Luke A Selth ${ }^{3,4}$ \\ 'Vancouver Prostate Centre, Vancouver, British Columbia, Canada \\ 2Department of Urologic Sciences, Faculty of Medicine, University of British Columbia, British Columbia, Canada \\ ${ }^{3}$ Flinders Centre for Innovation in Cancer, Flinders University, College of Medicine and Public Health, Bedford Park, South Australia, Australia \\ 4Dame Roma Mitchell Cancer Research Laboratories and Freemasons Foundation Centre for Men's Health, Adelaide Medical School, \\ The University of Adelaide, Adelaide, South Australia, Australia
}

Correspondence should be addressed to A Davies or L A Selth: adavies@prostatecentre.com or luke.selth@flinders.edu.au

This article was commissioned following sponsorship of the 7th PacRim Breast and Prostate Meeting by Endocrine-Related Cancer

\begin{abstract}
Tumours adapt to increasingly potent targeted therapies by transitioning to alternative lineage states. In prostate cancer, the widespread clinical application of androgen receptor (AR) pathway inhibitors has led to the insurgence of tumours relapsing with a neuroendocrine phenotype, termed neuroendocrine prostate cancer (NEPC). Recent evidence suggests that this lineage reprogramming is driven largely by dysregulation of the epigenome and transcriptional networks. Indeed, aberrant DNA methylation patterning and altered expression of epigenetic modifiers, such as EZH2, transcription factors, and RNA-modifying factors, are hallmarks of NEPC tumours. In this review, we explore the nature of the epigenetic and transcriptional landscape as prostate cancer cells lose their AR-imposed identity and transition to the neuroendocrine lineage. Beyond addressing the mechanisms underlying epithelial-to-neuroendocrine lineage reprogramming, we discuss how oncogenic signaling and metabolic shifts fuel epigenetic/ transcriptional changes as well as the current state of epigenetic therapies for NEPC.
\end{abstract}

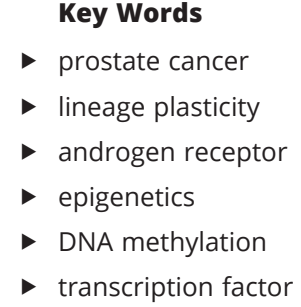

Endocrine-Related Cancer (2020) 27, R35-R50

\section{Introduction}

The androgen receptor (AR) is the principal driver of prostate cancer development and resistance; accordingly, AR pathway inhibitors (ARPIs) are used to treat men at all stages of the disease. Drug resistance ultimately ensues, which in most cases occurs through reactivation of the AR signaling axis. However, a subset of prostate tumours lose dependence on the AR pathway and co-opt alternative lineage programs to bypass therapeutic pressure and sustain tumour growth (Davies et al. 2018, Ku et al. 2019). Clinically, this lineage reprogramming has been associated with loss of luminal epithelial identity and the ensuing transition from a typical prostate adenocarcinoma to an aggressive neuroendocrine prostate cancer (NEPC)
(Beltran et al. 2016, Aggarwal et al. 2018). NEPC tumours are notable for attenuated AR signaling, pure or mixed small cell histology, and expression of neuroendocrine lineage markers (e.g. chromogranin A, neuron-specific enolase, and synaptophysin) (Ather et al. 2008, Aparicio et al. 2013). Recent studies have highlighted a rising incidence of NEPC in up to 15-20\% of advanced prostate cancer patients due, in part, to the widespread clinical integration of potent ARPIs, such as abiraterone acetate and enzalutamide (Aggarwal et al. 2018, Abida et al. 2019). The outlook for NEPC patients remains poor as there are no established therapeutic approaches for these tumours. 
To begin to dissect the molecular drivers of NEPC, genome-wide sequencing studies were undertaken between serial tumour samples from prostate cancer patients during the course of disease progression (Beltran et al. 2011, 2016). Apart from genomic loss of the tumour suppressors RB1 and TP53 (50-75\% in NEPC vs 5-15\% in adenocarcinoma), the overall spectrum of somatic mutations between adenocarcinoma and NEPC was found to be surprisingly similar (Beltran et al. 2016, Mu et al. 2017). Notably, the functional loss of RB1 and TP53 has been reported to facilitate the activation of pluripotency networks mediated, in part, through de-repression of the pluripotency transcription factor SOX2 as well as the epigenetic modifier, enhancer of zeste-homolog 2 (EZH2) (Choi et al. 2011, Kareta et al. 2015, Ku et al. 2017). Data from genetically engineered mouse models (GEMMs) support the notion that loss of $R B 1$ and/or TP53 fuels the development of neuroendocrine tumours (Ku et al. 2017, Zou et al. 2017); however, inactivation of RB1 is not tightly correlated with overt neuroendocrine differentiation in neoadjuvant hormone therapy-treated primary patient tumours (Sowalsky et al. 2018). This suggests that other mechanisms are required to co-operate with genomic alterations to re-direct cell fate toward the neuroendocrine lineage.

The paucity of unique genomic aberrations between prostate adenocarcinoma and NEPC strongly imply that the evolution to NEPC is driven by coordinated epigenetic and transcriptional reprogramming. In contrast to the genetic code, epigenetic programming is dynamically regulated by a series of enzymatic writers, erasers, and readers that impart a unique pattern of chemical marks superimposed on the genetic landscape. These epigenetic marks include DNA methylation and histone posttranslational modifications that alter chromatin structure and, in turn, gene expression programs to establish and maintain cell identity (Chen and Dent 2014). In NEPC, perturbed DNA methylation patterning and expression of epigenetic remodeling factors such as EZH2 and REST have been widely reported in pre-clinical models and patient tumours (Beltran et al. 2016, Ku et al. 2017, Li et al. 2017, Flores-Morales et al. 2019). Interplay between the epigenetic machinery and neuronal lineage-guiding transcription factors such as BRN2 (Bishop et al. 2017), ONECUT2 (Rotinen et al. 2018, Guo et al. 2019) and MYCN (encoding N-Myc) (Dardenne et al. 2016) may facilitate the emergent NEPC phenotype.

In this review, we introduce key concepts to understand how epigenetic and transcriptional dysregulation is a plausible driving mechanism in the reprogramming of prostate cancer cells as they lose their AR-imposed identity and transition toward the neuroendocrine lineage. Moreover, we discuss how oncogenic signaling and metabolic changes fuel epigenetic changes as well as the current state of epigenetic drugs for prostate cancer.

\section{The epigenetic basis of NEPC}

Currently available data indicate that NEPC can evolve from a prostate adenocarcinoma precursor following potent AR pathway inhibition (Lin et al. 2014, Beltran et al. 2016). Closer examination of patient tumours has revealed a spectrum of cellular differentiation states with the AR-positive luminal state and AR-indifferent neuroendocrine state at opposing ends of this cellular differentiation continuum. The existence of intermediate phenotypes, including hybrid/amphicrine and 'doublenegative' AR and neuroendocrine marker-expressing tumours, reinforces the notion that prostate cells can undergo phenotypic conversion (Papadimitriou et al. 1994, Aggarwal et al. 2016, Bluemn et al. 2017). However, whether this occurs via direct transdifferentiation or reversion to a metastable stem-like state followed by re-differentiation toward the neuroendocrine lineage remains unclear. Recent studies have reported heightened activity of stem cell-associated transcriptional programs as tumours progress to a terminal NEPC state (Smith et al. 2015, 2018, Lee et al. 2018), suggesting that these tumours co-opt stem cell programs to enhance plasticity and lineage conversion.

Epigenetic mechanisms, particularly DNA methylation and histone modifications, have a wellestablished role in regulating cell plasticity. Indeed, during normal development the epigenetic machinery is central to establishing unique chromatin patterns that guide lineage commitment. Disruption in these processes can yield impaired differentiation states and epigenetic reprogramming characteristic of malignant tumours (Nieto 2013). In particular, NEPC cell lines possess a unique chromatin accessibility profile, distinct from adenocarcinoma, which supports the activation of neuronal-associated gene networks (Park et al. 2018). This chromatin flux is regulated by RB1 and TP53, which act as gatekeepers to prevent neuroendocrine differentiation; concomitant loss in partially transformed prostate epithelial cells yields marked changes in chromatin accessibility resembling NEPC (Park et al. 2018).

Although the precise mechanisms are not well understood, inactivation of RB1 and/or TP53 leads to 
the upregulation of the DNA methyltransferase (DNMT) family member DNMT1 (McCabe et al. 2005, Lin et al. 2010). DNA methylation is a vital epigenetic modification that affects numerous biological processes, including transcription, cell fate decisions, and development (Greenberg \& Bourc'his 2019). Notably, relative to adenocarcinoma, DNMT1 is overexpressed in NEPC, and these tumours exhibit distinct DNA methylation patterns (Beltran et al. 2016, Smith et al. 2018). This is particularly evident at gene loci of known regulators of cell fate decisions (e.g. ASCL1 and HES6), epithelial-mesenchymal plasticity, and neuronal development. Functionally, DNA methylation systems are linked to the activity of Polycomb group (PcG) proteins, namely EZH2, which serve as a recruitment platform for DNMTs (Vire et al. 2006). The expression of both EZH2 and DNMT1 is tightly coupled to the re-activation of stem cell transcriptional programs in NEPC tumours (Clermont et al. 2015, Ku et al. 2017, Smith et al. 2018), suggesting that epigenetic changes generate a chromatin landscape that supports enhanced cell pliability and, in turn, neuroendocrine differentiation.

In addition to loss-of-function of RB1 and/or TP53, neuroendocrine lineage reprogramming is frequently associated with overexpression and/or amplification of MYCN, which encodes N-Myc (Beltran et al. 2011). $\mathrm{N}-\mathrm{Myc}$ has a well-established role in maintaining human embryonic stem cells as well as neural stem/progenitor cells (Varlakhanova et al. 2010). In the context of prostate cancer, forced expression of N-Myc in human prostate epithelial cells (along with AKT activation) yields aggressive tumours that histologically resemble NEPC and in which neuroendocrine markers are upregulated (Dardenne et al. 2016, Lee et al. 2016). Functionally, N-Myc is dependent on the bromodomain and extra-terminal domain (BET) family of epigenetic readers, in particular BRD4, to facilitate target gene expression (Henssen et al. 2016). BRD4 recognizes and binds acetylated lysine residues on histone tails leading to recruitment of the positive transcription elongation factor $\mathrm{b}$ (P-TEFb) which, in turn, phosphorylates RNA polymerase II to activate gene transcription. In this way, BRD4 maintains transcription of core stem cell genes such as OCT4 and NANOG as well as neuronal lineage gene sets, at least in part through interaction with Myc proteins (Puissant et al. 2013, Di Micco et al. 2014, Gonzales-Cope et al. 2016). In small cell lung cancer, BRD4 upregulates the expression of the neuronal lineage-guiding transcriptional factor ASCL1, rendering these tumours exquisitely sensitive to BET inhibition (Lenhart et al. 2015); whether this correlation holds true in NEPC is yet to be explored. In addition to
BRD4, N-Myc has recently been reported to cooperate with EZH2 to influence chromatin architecture and gene expression in MYCN-driven NEPC (Berger et al. 2019). The interplay and coordinated regulation of epigenetic factors highlight the complexity in the dynamics of the epigenetic landscape in NEPC.

\section{Interplay between the epigenetic landscape and metabolism}

Modulation of the epigenome is tightly coupled to metabolic reprogramming in cancer cells; many of the chemical modifications on DNA and histones derive from intermediates of cellular metabolic pathways (Schvartzman et al. 2018). For example, pyruvate generated from glycolysis is the main substrate for acetyl-CoA, a central metabolite coordinating the activity of the histone acetyltransferase (HAT) enzymes. Treatment-induced NEPC tumours exhibit elevated expression of the histone lysine demethylase KDM8, which functions to reprogram metabolism toward aerobic glycolysis (Wang et al. 2019). Moreover, MYCN, which is implicated in neuroendocrine lineage reprogramming, increases mitochondrial export of acetyl groups and upregulates the HAT GCN5 leading to elevated histone acetylation and DNA accessibility (Knoepfler et al. 2006). This may explain why NEPC tumours are highly glycolytic, and inhibition of glucose metabolism leads to reduced proliferation and reversion of resistance phenotypes (Li et al. 2016, Choi et al. 2018).

In addition to the heightened rate of glycolysis in NEPC, increased glutamine uptake can further increase the generation of pyruvate and, in turn, acetyl-CoA. Interestingly, epigenetic alterations in prostatic cancerassociated fibroblasts (CAFs) have been reported to promote glutamine secretion into the tumour microenvironment (Mishra et al. 2018). This process was modulated by oncogenic Ras activity resulting from epigenetic silencing of the Ras inhibitor RASAL3 in CAFs; treatment with the demethylating agent 5-aza-2'-deoxycytidine (decitabine) rescued RASAL3 expression. In 3D co-cultures of CAF-CWR22Rv1 prostate adenocarcinoma cells, increased glutamine secretion by CAFs following ARPI treatment induced neuroendocrine differentiation, which could be abrogated by antagonizing glutamine uptake (Mishra et al. 2018). In support of these findings, prostate cancer patients progressing on ARPIs exhibit elevated blood glutamine levels compared to those who have therapeutically responsive disease (Koochekpour et al. 2012, Mishra et al. 2018). 
Most recently, profiling of adenocarcinoma and NEPC tumours identified NEPC-specific upregulation of the metabolic enzyme phosphoglycerate dehydrogenase (PHGDH) (Reina-Campos et al. 2019), which is the first and limiting step in the serine, glycine, one-carbon pathway (SGOCP). SGOCP activity is required for the biosynthesis of S-adenosyl methionine (SAM), the source of methyl groups that are used for DNA and histone methylation (Yang \& Vousden 2016). Mechanistically, the loss of atypical protein kinase $\mathrm{C}$ (PKC) $\lambda / \iota$ in prostate adenocarcinoma fuels increased SGOCP activity, leading to aberrant DNA methylation patterns that mimic those observed in NEPC patient tumours (Reina-Campos et al. 2019). Together, these studies suggest that NEPC differentiation is dependent on metabolic reprogramming to feed epigenetic changes that favor this lineage conversion (as depicted in Fig. 1).

\section{EZH2 as a master regulator of NEPC reprogramming}

The epigenetic modulator EZH2 is frequently overexpressed in patients who have progressed to NEPC (Beltran et al. 2011, 2016). EZH2 is the catalytic subunit of the Polycomb repressive complex 2 (PRC2), which mediates the deposition of restrictive histone marks, namely trimethylation of histone $\mathrm{H} 3$ at lysine 27 (H3K27me3), to repress lineage-specifying factors thereby promoting a more stem-like state (Lee et al. 2006). Early work in prostate cancer correlated EZH2 with poorer outcomes (Varambally et al. 2002), and more recently heightened EZH2 expression and activity (e.g. H3K27me3 expression) has been reported in the majority of NEPC patients (87\% vs $46 \%$ adenocarcinoma) (Clermont et al. 2015, Beltran et al. 2016, Puca et al. 2018).

In support of EZH2 as a central regulator of epigenetic rewiring in NEPC, inhibition of EZH2 in prostate adenocarcinoma cell lines precludes ARPImediated neuroendocrine differentiation (Zhang et al. 2018, Shan et al. 2019). Moreover, GEMM models driven by overexpression of MYCN (Dardenne et al. 2016) or deletion of RB1 (Ku et al. 2017) exhibit activation of neuroendocrine and stem cell transcriptional programs along with increased expression of EZH2. Notably, these tumours were sensitive to EZH2 inhibitors, and inhibition of EZH2 re-activated the canonical AR signaling axis, thereby sensitizing tumours to ARPIs (Dardenne et al. 2016, Ku et al. 2017). A similar dependency on EZH2 has been described in NEPC cell lines (Crea et al. 2011, Zhang et al. 2018, Shan et al. 2019), patient-derived xenografts (Kleb et al. 2016), and organoids (Puca et al. 2018);

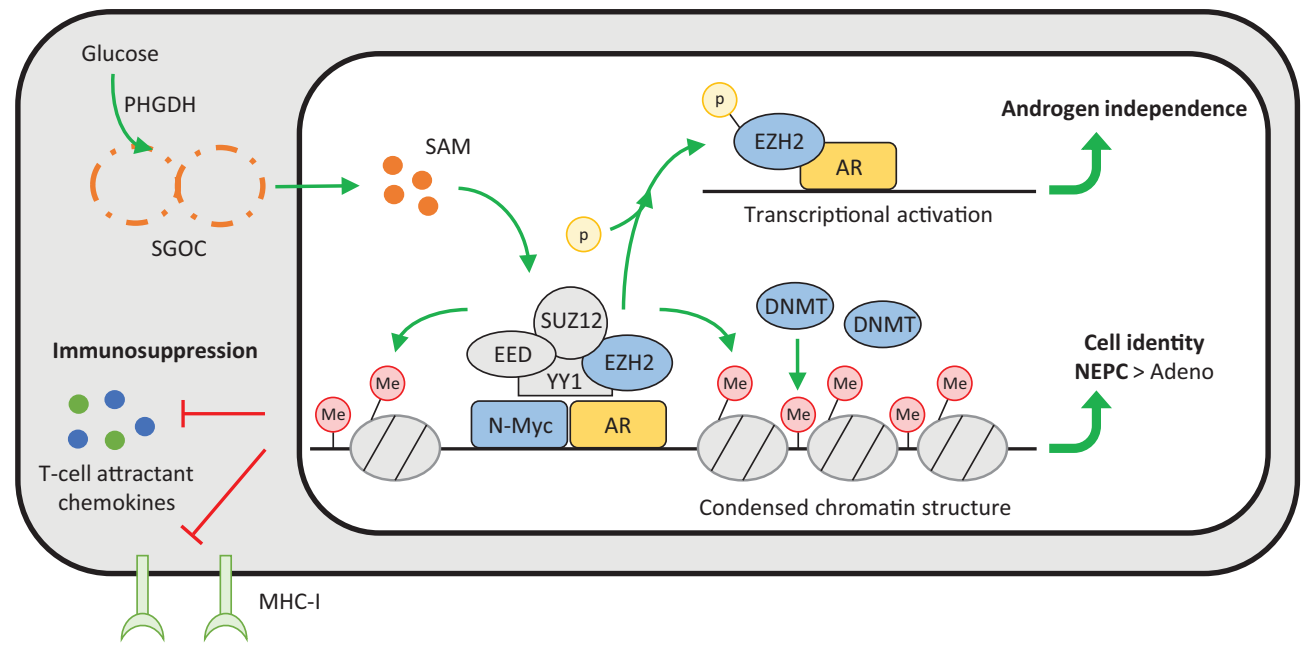

Figure 1

EZH2 is a master regulator of neuroendocrine lineage plasticity in prostate cancer. EZH2 functions as the catalytic subunit within the Polycomb repressive complex 2 (PRC2) to tri-methylate histone $\mathrm{H3}$ at lysine 27 resulting in a condensed chromatin structure and repression of gene networks. This state is reinforced by EZH2 recruitment of DNA methyltransferases (DNMTs). Metabolic reprogramming in NEPC underlies the epigenetic re-wiring; increased glucose shutting through the serine, glycine, one-carbon (SGOC) pathway increases intracellular S-adenosyl methionine (SAM) - the fuel for EZH2 and DNMT enzymes. The resulting change in the chromatin architecture facilitates the conversion of an adenocarcinoma to the neuroendocrine lineage. $\mathrm{N}-\mathrm{Myc}$ and AR guide EZH2 to silence genes governing the epithelial lineage identity. In addition, EZH2-mediated repression of T-cell attractant chemokines (e.g. CXCL9 and CXCL10) and the antigen presentation machinery potentiates a 'cold' immunosuppressive tumour microenvironment. Aberrant oncogenic signaling can yield EZH2 phosphorylation, which switches the enzyme from a Polycomb repressor to a transcriptional co-activator, functioning with the AR to support androgen-independent phenotypes. 
however, complete phenotypic reversion to an AR-driven adenocarcinoma following EZH2 inhibition appears to be context dependent. More specifically, pre-clinical NEPC models retaining AR expression are particularly plastic and sensitive to combination therapy with EZH2 inhibitors and ARPIs, irrespective of genetic background (e.g. RB1 loss or N-Myc overexpression) (Dardenne et al. 2016, Ku et al. 2017). Conversely, AR-negative NEPC organoids could not be reprogrammed back to an adenocarcinoma state following EZH2 inhibition, and no additive or synergistic effects were observed with enzalutamide (Puca et al. 2018). This suggests that epigenetic inhibitors may exhibit the greatest efficacy in a therapeutic window before tumours lose AR expression.

Functionally, EZH2 co-operates with lineage-guiding transcription factors to epigenetically regulate gene expression and coordinate lineage specification. In NEPC, EZH2 directly complexes with N-Myc to transcriptionally repress genes that enforce an AR-driven adenocarcinoma state (Dardenne et al. 2016). Accordingly, conditional expression of N-Myc (along with activated AKT) in prostate epithelial cells is sufficient to induce neuroendocrine differentiation (Dardenne et al. 2016, Lee et al. 2016). $M Y C N$-amplified neuroblastomas are absolutely dependent on EZH2 for growth and survival (Chen et al. 2018), suggesting that the interplay between N-Myc and EZH2 drives the activation of neuronal programs. Further studies in prostate cancer identified N-Myc at neuronal lineage-associated gene promoters harboring both repressive H3K27me3 and active H3K4me3 histone marks (termed bivalent chromatin). EZH2 was required to maintain bivalency at N-Myc-bound genes, and its knockdown led to de-enrichment of neuronal-associated pathways in NEPC organoids (Berger et al. 2019).

EZH2 has also been reported to synergize with other epigenetic modification systems to promote chromatin remodeling that is necessary to enforce a state of lineage plasticity. EZH2 has been linked to DNMT activity and may pre-mark genes for de novo DNA methylation (Vire et al. 2006, Schlesinger et al. 2007), potentially via a scaffolding mechanism mediated by the long ncRNA HOTAIR (Xiang et al. 2018). The EZH2:DNMT complex is not well studied in prostate cancer; however, in breast cancer, EZH2 targets DNMT1 to the promoter of genes involved in Hippo signaling to enhance epithelial-mesenchymal plasticity and stem-like phenotypes (Liu et al. 2018). Similarly, a tight association and functional link exists between EZH2 and the H3K36me2 methyltransferase nuclear receptor binding SET domain protein 2 (NSD2). NSD2 is highly expressed in NEPC (Aytes et al. 2018) and functions to reprogram the epigenome by re-directing EZH2 binding to demarcate focal H3K27me3 domains (Zheng et al. 2012, Popovic et al. 2014). The activity of NSD2 is regulated by EZH2 and, in turn, is required for EZH2-mediated oncogenic programming in prostate cancer models (Asangani et al. 2013).

Likewise, EZH2 functions with lysine-specific demethylase 1 (LSD1), a dual histone H3K4 and H3K9 demethylase. The long ncRNA HOTAIR acts as a scaffold to tether EZH2 and LSD1 (Tsai et al. 2010), which act coordinately at bivalent chromatin domains to enforce a state of heightened cell plasticity via concerted repression of developmental genes (Adamo et al. 2011). LSD1 can also demethylate and stabilize non-histone substrates, such as DNMT1 (Wang et al. 2009a), as well as having functions entirely independent of its enzymatic activity; indeed, in prostate cancer, LSD1 collaborates with ZNF217 to activate gene networks involved in the regulation of stem cell phenotype in a demethylaseindependent manner (Sehrawat et al. 2018). Notably, mimicking EZH2 inhibition, silencing LSD1 re-activates the AR-driven epithelial differentiation program in androgen-independent cell lines (Sehrawat et al. 2018). In small cell lung cancer, LSD1 inhibitors reduced expression of neuroendocrine lineage genes and caused complete tumour regression in a patient-derived mouse model (Augert et al. 2019); whether NEPC is similarly addicted to LSD1 is yet to be explored.

Emerging studies are beginning to shed light on how EZH2-mediated epigenetic reprogramming facilitates neuroendocrine differentiation. In particular, EZH2 can be activated by transcription factor 4 (TCF4), a key transcription factor in Wnt/ $\beta$-catenin signaling, leading to the deposition of repressive H3K27me3 histone marks along the microRNA miR-708 promoter (Shan et al. 2019). Silencing miR-708 relieves its inhibition of neuronatin (Ryu et al. 2013), a mediator of neuronal differentiation, as well as the stem cell-like factor CD44 (Saini et al. 2012). Elevated Wnt signaling is a feature of NEPC tumours (Yang et al. 2005), and inhibiting TCF4 prevented adenocarcinoma-to-NEPC conversion following androgen deprivation (Shan et al. 2019). Moreover, EZH2 activity has been reported to be coupled to cAMP-response element binding protein (CREB) activation in prostate cancer models; CREB-induced H3K27me3, and neuroendocrine differentiation could be blocked by EZH2 inhibition (Zhang et al. 2018). Mechanistically, activation of the CREB/EZH2 axis facilitates epigenetic repression of the anti-angiogenic factor thrombospondin-1 (TSP1) leading to overt angiogenesis and neuroendocrine features in 
prostate tumour xenografts (Zhang et al. 2018). Finally, the MEK/ERK pathway governs EZH2 transcriptional upregulation and recruitment to the E-cadherin promoter, thereby facilitating epithelial-mesenchymal plasticity and expansion of prostate cancer stem/progenitor cells (Cai et al. 2012, Nolan et al. 2015). These studies nominate EZH2 as a central hub integrating oncogenic signaling cascades to reprogram the epigenetic landscape in support of lineage plasticity and neuroendocrine differentiation.

Although EZH2 is highly expressed in NEPC, these tumours often exhibit a more relaxed chromatin structure (Park et al. 2018). To resolve this paradox, recent evidence suggests that the function of EZH2 extends beyond PRC2 and histone methylation. In androgen-independent prostate cancer (AIPC), EZH2 has been reported to interact with the AR to transcriptionally activate target gene expression (Xu et al. 2012, Kim et al. 2018). In these tumours, the AR does not function canonically but is 'reprogrammed' to execute a distinct transcriptional program (Wang et al. 2009b); for example, the AR is selectively recruited to the promoter of the gene encoding UBE2C, a cell cycle checkpoint inhibitor that is highly upregulated in both AIPC and NEPC tumours (Tzelepi et al. 2012). Re-directing AR transcriptional output may be regulated by the local chromatin environment mediated, in part, by AR interaction with EZH2 (Kim et al. 2018). EZH2 has also been reported to interact with and regulate the transcriptional activity of STAT3 (Kim et al. 2013), the nuclear factor $\mathrm{\kappa B}$ (NF-кB) pathway (Lee et al. 2011), and the SWI/SNF chromatin remodeling complexes (Kim et al. 2015). Further mechanistic studies are required to address the duality between the canonical, PRC2-bound and non-canonical functions of EZH2 during emergent NEPC, which are summarized in Fig. 1.

\section{Epigenetic reprogramming of AR function in NEPC}

While the canonical AR signaling axis is attenuated in NEPC, recent clinical data from the West Coast SU2C-PCF Dream Team has highlighted persistent AR expression in a subset of patients with histologically small cell/ neuroendocrine prostate tumours (Aggarwal et al. 2018). This is suggestive of a differentiation continuum and that an alternative AR transcriptional program may exist during emergent NEPC.

The AR cistrome is fluid and influenced by the local chromatin structure. In particular, the AR preferentially binds nucleosome-deprived regions (Jia et al. 2008), suggesting that preceding chromatin remodeling exposes otherwise transcriptionally restricted AR binding sites. In support of this notion, expression of the pioneer transcription factors FOXA1 and HOXB13 - which are capable of binding highly compacted chromatin regions to promote a permissive chromatin structure - in prostate epithelial cells yields reprograming of the AR cistrome to resemble that of a prostate tumour (Pomerantz et al. 2015). However, the mechanisms underlying FOXA1-mediated AR reprogramming remain unclear. FOXA1 signaling can be dynamically regulated by co-factors; for example, the pluripotency reprogramming factor NANOG re-directs the FOXA1:AR complex to activate stem cell-associated networks (Jeter et al. 2016). A candidate AR reprogramming factor in NEPC is another Forkhead Box A pioneer factor, FOXA2, which is expressed almost exclusively in NEPC tumours (75\% NEPC vs $4 \%$ adenocarcinoma) (Park et al. 2017). FOXA2 is not only enriched in NEPC but also co-expressed with the rare synaptophysin-positive cells in the adult prostate (Mirosevich et al. 2006). Earlier work by Matusik and colleagues revealed that FOXA2 expression is restricted primarily to basal cells during early prostate development, whereas FOXA1 is broadly expressed throughout the epithelium from early development to maturity (Gao et al. 2005). This spatially and temporally distinct expression pattern is unlike other endodermal organs, such as lung and liver, in which these factors tend to be co-expressed. Collectively, these findings are indicative of distinct functionalities of FOXA1 and FOXA2 in prostate cancer and support a role for the latter in NEPC; however, whether changes to the FOXA1:FOXA2 ratio can elicit AR cistrome reprogramming to support a NEPC phenotype is an open question.

The AR can directly recruit histone modifiers to influence chromatin architecture and gene expression. LSD1 is an important regulator of AR transcriptional activity, facilitating the suppression of canonical AR target genes via H3K4 demethylation (Cai et al. 2011). Interestingly, LSD1/AR binding and transactivation are reprogrammed by RB1 loss, which may have important implications for NEPC (Liang et al. 2017). Similarly, the BET family, in particular BRD4, interact with the AR to promote chromatin de-compaction and nucleosome eviction in aggressive prostate cancer (Urbanucci et al. 2017). A recent study showed that BET inhibition disrupts the recruitment of BRD4 to AR target gene loci (Faivre et al. 2017) and can re-sensitize enzalutamide-resistant prostate cancer to ARPIs (Asangani et al. 2016).

AR activity can be directly regulated by epigenetic modifiers. A variety of histone deacetylases (HDACs), 
such as SIRT1, are capable of deacetylating the AR and thereby preventing association with the transcriptional co-activator p300 (Fu et al. 2006). Notably, SIRT1 is upregulated in NEPC, and its forced expression in prostate adenocarcinoma cell lines promotes neuroendocrine differentiation (Ruan et al. 2018). Further studies are warranted to delineate how reciprocity between epigenetic modifiers and the AR facilitates a chromatin architecture to support the NEPC phenotype.

\section{Interplay between transcription factors and the epigenome in NEPC}

FOXA1 is a transcription factor that is required for the development and maintenance of epithelial cells in the prostate (DeGraff et al. 2014), a function related to its role as a pioneer factor for AR (Jozwik and Carroll 2012). In concordance with its role in maintaining the epithelial phenotype, FOXA1 is down-regulated in NEPC and its loss in cell line models of prostate cancer drives neuroendocrine differentiation (Kim et al. 2017). Mechanistically, this occurs, at least in part, via de-repression of the FOXA1 target gene $I L 8$, leading to activation of the MAPK/ERK pathway and neuron-specific enolase (ENO2) expression (Kim et al. 2017). Notably, FOXA1 mutations are common in prostate cancer. While the majority of these mutations enhance AR activity and promote an exaggerated proluminal differentiation program (Adams et al. 2019, Parolia et al. 2019), mutation of R219 modifies FOXA1 binding activity and hence pioneering function, resulting in altered chromatin accessibility throughout the genome that ultimately activates a transcriptional program associated with mesenchymal and neuroendocrine phenotypes (Adams et al. 2019). Thus, whereas wildtype FOXA1 suppresses lineage plasticity in the prostate, mutant forms of this key pioneer factor can have opposing functions.

Aberrant expression and/or activity of neuronal lineage-guiding transcription factors occurs concomitantly with loss of AR and FOXA1 in NEPC. BRN2 (also known as POU3F2) is a member of the PitOct-Unc (POU)-domain family with a well-described role in neural differentiation that was recently implicated in NEPC (Bishop et al. 2017). It is overexpressed in this disease subtype relative to adenocarcinoma and directly drives neuroendocrine differentiation by enhancing the expression of SOX2. Moreover, BRN2 and SOX2 physically interact and act coordinately on chromatin to activate the expression of neural genes (Bishop et al.
2017). As mentioned, SOX2 is more highly expressed in metastatic CRPC tumours that exhibit loss of TP53 and RB1 (Mu et al. 2017), but whether this phenomenon is mediated by BRN2 is currently unknown. Notably, SOX2 is part of the 'reprogramming cocktail' of four pioneer transcription factors that together are capable of converting differentiated fibroblasts into induced pluripotent stem cells (Takahashi \& Yamanaka 2016). More recently, another POU-domain transcription factor, BRN4, was found to interact with BRN2 and enhance its regulation of SOX2 (Bhagirath et al. 2019). Importantly, BRN2 is directly repressed by AR, an example of the extensive, direct interplay that occurs between the key factors controlling cell identity in prostate cancer (Fig. 2).

ASCL1 (also referred to as MASH-1) is another neuralspecific transcription factor that was first implicated in NEPC by immunohistochemical analysis of tumour samples, which showed upregulation in tumours with neuroendocrine differentiation (Rapa et al. 2008). Subsequent work demonstrated that ASCL1 was sufficient to promote neuroendocrine differentiation in LNCaP cells (Rapa et al. 2013). Although the precise mechanisms by which it facilitates neuronal lineage reprogramming remain to be elucidated, ASCL1 was identified as a transdifferentiation factor in the context of induced fibroblast-to-neuron conversion (Vierbuchen et al. 2010). Like FOXA1/2, ASCL1 acts as a pioneer factor to bind closed chromatin; via this function, it can recruit BRN2 to chromatin to regulate a reprogramming-associated transcriptional signature (Vierbuchen et al. 2010). Of relevance to NEPC, ASCL1 is also activated in small cell lung cancer where it promotes Wnt signaling and CDK5catalyzed phosphorylation (and hence inactivation) of RB1 (Meder et al. 2016).

Two distinct methodologies for identification of NEPC drivers using clinical transcriptomic data discovered ONECUT2, which appears to have a complex, multifaceted role in neuroendocrine differentiation (Rotinen et al. 2018, Guo et al. 2019). ONECUT2 suppresses the AR signaling pathway by both down-regulating $A R$ gene expression and antagonizing chromatin-bound AR activity at the promoters of a subset of androgen-regulated genes (e.g. KLK3) (Rotinen et al. 2018). It also directly represses FOXA1 gene expression (Rotinen et al. 2018), further highlighting the complex interplay between transcription factors in prostate cancer (Fig. 2). In addition to the repression of genes that enforce the epithelial lineage, ONECUT2 directly activates neuroendocrine lineage markers such as PEG10 (Rotinen et al. 2018). Finally, ONECUT2 regulates the genome-wide association of HIF1 $\alpha$ with chromatin https://erc bioscientifica com

https://doi.org/10.1530/ERC-19-0420 (c) 2020 Society for Endocrinology Published by Bioscientifica Ltd. Printed in Great Britain 


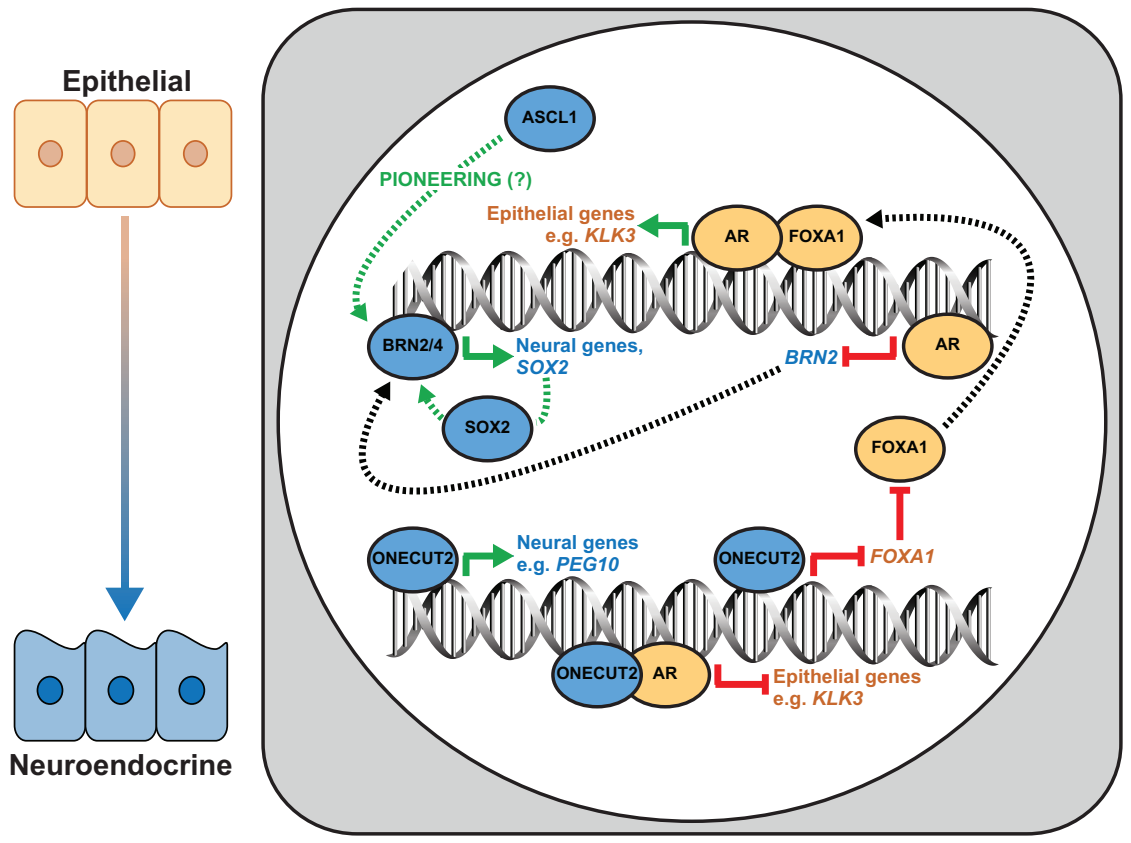

\section{Figure 2}

Interplay between transcription factors in neuroendocrine transdifferentiation.

Transcription factors that enhance or repress neuroendocrine lineage plasticity are shown in blue and orange, respectively. Activating vs repressing effects are indicated by green and red lines/arrows, respectively. via direct regulation of SMAD3, leading to a synergistic effect with hypoxia on neuroendocrine plasticity (Guo et al. 2019). Interestingly, another NEPC-associated transcription factor, FOXA2, also cooperates with HIF1 $\alpha$ to regulate pro-plasticity factors such as SOX9 and the histone demethylase JMJD1A (KDM3A) (Qi et al. 2010). Indeed, more recent studies have revealed that JMJD1A is a key integrator of hypoxia-associated signals, leading to altered histone methylation patterns that provoke a neuroendocrine transcriptional program (Maina et al. 2016, 2017)

Given the similarities between neuroendocrine lineage plasticity and epithelial-mesenchymal transition (EMT; (Davies et al. 2018)), it is not surprising that EMTassociated transcription factors have been implicated in NEPC. Indeed, ZEB1 (Viswanathan et al. 2017), Snail (McKeithen et al. 2010), Slug (Esposito et al. 2015), and FOXC2 (Paranjape et al. 2016) can all promote the emergence of neuroendocrine features, highlighting the convergent transcriptional networks involved in this process and EMT. An obvious implication of this convergence is that new therapies being developed to target EMT in cancer (Du \& Shim 2016) could be harnessed for NEPC; as examples, targeting Notch (e.g. rovalpituzumab tesirine, tarextumab) and stem-ness (i.e. disulfiram, an inhibitor of ALDH, which is highly expressed by cancer stem cells) are promising strategies for both. Translation of these approaches and the eventual impact on cancer patients will undoubtedly be facilitated by a more comprehensive understanding of the similarities and differences - epigenetic, transcriptional, and other - between these two different manifestations of lineage plasticity.

In summary, transcription factors play a critical role in prostate cancer cell lineage plasticity. In theory, transcription factors that can engage their target sites on nucleosomal DNA and thereby act as pioneer factors to initiate transcriptional regulation at sites of closed chromatin (e.g. FOXA1, SOX2, and ASCL1) would act as the master controllers of such plasticity. However, the extensive interplay between these factors, summarised in Fig. 2, suggests that this concept is simplistic. Unraveling this interplay and deciphering the relationships between transcription factor function, epigenetic alterations, and microenvironmental cues will be challenging but is crucial to identify the most effective therapeutic strategies for NEPC.

\section{Post-transcriptional regulation of neuroendocrine lineage reprogramming}

While transcription factors are likely to be the most influential regulators of gene expression, posttranscriptional mechanisms also play a crucial role in controlling the ultimate output of a functional protein product. Indeed, post-transcriptional mechanisms such as mRNA splicing appear to significantly influence the transcriptional networks that arise during the transition from adenocarcinoma to NEPC. SRRM4 is a splicing factor (c) 2020 Society for Endocrinology Published by Bioscientifica Ltd. Printed in Great Britain 
specifically required for neural cell differentiation that was found to be elevated in NEPC (Zhang et al. 2015) and, by careful analysis of whole-transcriptome sequencing data, implicated in the majority ( $>66 \%$ ) of splicing alterations seen in this disease state (Li et al. 2017). Key targets of SRRM4 include REST, a negative regulator of neurogenesis (Li et al. 2017), as well Bif-1 (Gan et al. 2018), MEAF6 (Lee et al. 2017), and the histone demethylase BHC80 (Li et al. 2019). The identities and roles of other splicing factors beyond SRRM4 that contribute to neuroendocrine lineage plasticity remain to be determined.

Post-transcriptional gene regulation by miRNAs is another 'epigenetic' mechanism that influences transcriptional networks during progression to NEPC. By targeting PP2R3A, a regulatory subunit of the tumour suppressor PP2A, overexpression of miR-652 promotes neuroendocrine differentiation, EMT, and metastasis in prostate cancer cell lines (Nam et al. 2018). Similarly, an EMT-promoting metastamiR, miR-194 (Das et al. 2017), can elicit neuronal phenotypes in prostate cancer; importantly, targeting miR-194 blocks neuroendocrine differentiation and the growth of NEPC-like patientderived organoids (Fernandes RC, Toubia J, Townley S, Hanson AR, Dredge BK, Pillman KA, Bert AG, Iggo R, Das $\mathrm{R}$, Obinata $\mathrm{D}$, et al., unpublished observations; https:// doi.org/10.1101/752709). Collectively, these findings reveal another layer of complexity in the epigenetic and transcriptional regulation of prostate cancer lineage plasticity and nominate miRNAs as another class of therapeutic targets in NEPC.

\section{Post-translational regulation of epigenetic modifiers}

Post-translational modification of epigenetic modifiers represents another layer of regulatory control of prostate cancer lineage plasticity and neuroendocrine differentiation. For example, EZH2 has been reported to act as both a transcriptional repressor and an activator in aggressive prostate cancer (Xu et al. 2012, Kim et al. 2018). This paradox may be attributed to post-translational modification of EZH2; AKT-mediated phosphorylation of EZH2 at serine-21 shifts EZH2 from a transcriptional repressor to a co-activator of the $\mathrm{AR}$ in androgenindependent prostate cancer (Xu etal.2012). Enhanced AKT signaling is characteristic of NEPC (Dardenne et al. 2016). Similarly, EZH2 phosphorylation at threonine-311 by AMP-activated protein kinase (AMPK), a metabolic sensor activated by an energy deprivation state, attenuates EZH2- mediated epigenetic silencing by disrupting the Polycomb complex (Wan et al. 2018). Activation of AMPK is essential for hypoxia-induced neuroendocrine differentiation in prostate cancer cell lines (Lin et al. 2016b), thus linking EZH2 activity to metabolic reprogramming and emergent NEPC.

DNMTs are also regulated by post-translational modifications. Cross-talk between adjacent residues on DNMT1, lysine-142 methylation by SET7, and serine-143 phosphorylation by AKT regulates DNMT1 stability, with the phosphorylated form being more stable (Esteve et al. 2011). DNMT1 activity is also linked to functional RB1 loss; inactivation of RB1 allows ATM to directly bind DNMT1, leading to decreased DNMT1 stability via sequential acetylation and ubiquitylation (Shamma et al. 2013). Altered DNMT1 stability in turn results in abnormal DNA methylation patterning, including at genes implicated in neuroendocrine reprogramming such as FOXA1 and LHX2 (Shamma et al. 2013).

PKC $\alpha$-mediated phosphorylation of LSD1 at serine- 112 is required for its chromatin binding and demethylase activity. Of note, phosphorylated LSD1 targets H3K4 at the $C D H 1$ (E-cadherin) promoter to repress transcription, thereby facilitating epithelial-mesenchymal plasticity and a metastatic phenotype (Feng et al. 2016). In short, posttranslational modification of epigenetic modifiers appears to play an influential role in NEPC, and further work in this area will likely reveal novel therapeutic targets.

\section{Targeting epigenetic and transcriptional regulators in NEPC}

As our understanding of the NEPC epigenome advances, the prospect of targeting epigenetic mechanisms to reverse or delay neuroendocrine lineage transformation is beginning to show promise. The correlation between specific methylation patterns and high EZH2 levels in NEPC, and the association between these tumours and heightened cell plasticity, provide a rationale for development of epigenetic targeting strategies. Recent pre-clinical and clinical studies support this notion, as summarized in Table 1.

The transition from adenocarcinoma to NEPC is accompanied by a shift in the DNA methylation landscape (Beltran et al. 2016). As described, this is in part due to metabolic reprogramming leading to aberrant SAM production, the fuel for DNMT enzymes (Reina-Campos et al. 2019). In pre-clinical models, DNMT inhibition re-sensitized hormone-refractory, neuroendocrine-like 
prostate cancer cell lines, and xenografts to ARPIs (Gravina et al. 2008, 2010, Reina-Campos et al. 2019). These results suggest that inhibition of DNMTs may be an attractive therapeutic strategy for patients with NEPC. Notably, the DNMT inhibitors decitabine and azacytidine are already approved by the FDA for treatment of myelodysplastic syndromes and could therefore be rapidly re-positioned for NEPC. However, in phase II clinical trials in CRPC, DNMT inhibitors did not elicit a strong, single agent antitumour response, although these trials were small and without molecular biomarker selection (Thibault et al. 1998, Sonpavde et al. 2011). Future clinical trials will be needed to assess the efficacy of DNMT-directed therapies in NEPC patients, possibly using loss of $P K C \lambda / 1$ as a biomarker of DNMT dependency.

One of the most well-documented dysregulated epigenetic factors in NEPC is EZH2 (Clermont et al. 2015, Beltran et al. 2016). In pre-clinical NEPC models, treatment with EZH2 inhibitors reversed the neuroendocrine phenotype established by drivers of lineage plasticity, namely N-Myc (Dardenne et al. 2016, Berger et al. 2019) or RB1/TP53 loss (Ku et al. 2017), and re-sensitized tumours to the ARPI enzalutamide. These studies are currently being translated through clinical trials testing EZH2 inhibitors. In particular, the EZH2 inhibitor PF-06821497 is currently being tested in a phase I dose-escalation study in patients with advanced/metastatic CRPC (NCT03460977). Likewise, the phase Ib/II ProSTAR trial is assessing the utility of combining the EZH2 inhibitor CPI-1205 with enzalutamide or abiraterone/prednisone in patients with metastatic CRPC (NCT03480646). Clinical activity has been reported in both the enzalutamide and abiraterone arms with $\geq 80 \%$ PSA reductions in $20-30 \%$ of patients, and $40-75 \%$ of patients achieved stable disease control. Aurora A inhibitors such as alisertib (MLN8237), which result in destabilization of N-Myc, have also shown some promise in clinical trials. A phase II clinical trial of alisertib in NEPC patients reported a modest clinical benefit, with a 2.3 month improvement in progressionfree survival (NCT01799278). A second phase I/II clinical trial of alisertib in combination with abiraterone in CRPC with neuroendocrine differentiation was terminated early due to toxicity and lack of clinical benefit; however, a decrease in neuroendocrine marker expression was reported in a subset of patients (NCT01848067) (Lin et al. 2016a).

Table 1 Clinical trials for epigenetic therapies in prostate cancer.

\begin{tabular}{|c|c|c|c|c|}
\hline Mechanism & Agent & $\begin{array}{l}\text { Clinical } \\
\text { status }\end{array}$ & Clinical Trial ID & Outcome \\
\hline \multirow[t]{4}{*}{ DNMT inhibition } & Azacitidine & II & $\overline{\text { NCT00384839 }}$ & $\begin{array}{l}\text { PSA doubling time } \geq 3 \text { months in } 19 / 34 \\
\text { hormone-refractory CRPC patients }\end{array}$ \\
\hline & $\begin{array}{l}\text { Azacitidine + chemotherapy } \\
\text { (docetaxel/prednisone) }\end{array}$ & II & NCT00503984 & $\begin{array}{l}\text { PSA response in 10/19 hormone- } \\
\text { refractory } \mathrm{MCRPC} \text { patients; significant } \\
\text { demethylation of GADD } 45 A\end{array}$ \\
\hline & Decitabine + ARPI (enzalutamide) & I/II & NCT03709550 & Recruiting mCRPC; no results reported \\
\hline & $\begin{array}{l}\text { SGI-110 + immunotherapy } \\
\text { (pembrolizumab) }\end{array}$ & 1 & NCT02998567 & $\begin{array}{l}\text { Recruiting relapsed/refractory CRPC; no } \\
\text { results reported }\end{array}$ \\
\hline \multirow[t]{4}{*}{$\mathrm{EZH} 2$ inhibition } & Tazemetostat & ॥ & NCT02875548 & $\begin{array}{l}\text { Ongoing; well tolerated in B-cell } \\
\text { lymphoma and advanced solid } \\
\text { tumours }\end{array}$ \\
\hline & PF-06821497 & I & NCT03460977 & $\begin{array}{l}\text { Recruiting relapsed/refractory CRPC; no } \\
\text { results reported }\end{array}$ \\
\hline & $\begin{array}{l}\text { CPI-1205 + ARPI (enzalutamide or } \\
\text { abiraterone/prednisone) }\end{array}$ & $\mid / I I$ & NCT03480646 & Recruiting mCRPC; no results reported \\
\hline & CPI-1205 + immunotherapy (ipilimumab) & $|/| \mid$ & NCT03525798 & $\begin{array}{l}\text { Recruiting advanced solid tumours; no } \\
\text { results reported }\end{array}$ \\
\hline N-Myc inhibition & MLN8237 & II & NCT01799278 & $\begin{array}{l}\text { Progression-free survival of } 2.3 \text { months } \\
\text { in NEPC arm }\end{array}$ \\
\hline \multirow[t]{3}{*}{ BET inhibition } & ZEN003694 + ARPI (enzalutamide) & $|/ I|$ & NCT02711956 & Ongoing in $\mathrm{mCRPC}$, no results reported \\
\hline & GS-5829 + ARPI (enzalutamide) & $\mid / I I$ & NCT02607228 & Ongoing in MCRPC; no results reported \\
\hline & OTX015 & I & NCT02698176 & Terminated; limited efficacy \\
\hline \multirow[t]{3}{*}{ LSD1 inhibition } & INCB059872 & $\mid / I I$ & NCT02712905 & $\begin{array}{l}\text { Recruiting, including a NE arm; no } \\
\text { results reported }\end{array}$ \\
\hline & Phenelzine & II & NCT02217709 & $\begin{array}{l}\text { Recruiting in localized prostate cancer; } \\
\text { no results reported }\end{array}$ \\
\hline & Phenelzine + chemotherapy (docetaxel) & II & NCT01253642 & Terminated; low enrollment \\
\hline
\end{tabular}

ARPI, androgen receptor pathway inhibitor; BET, bromodomain and extra-terminal motif; CRPC, castration-resistant prostate cancer; DNMT, DNA methyltransferase; $\mathrm{MCRPC}$, metastatic castration-resistant prostate cancer; NE, neuroendocrine; NEPC, neuroendocrine prostate cancer.

(c) 2020 Society for Endocrinology Published by Bioscientifica Ltd. Printed in Great Britain 
Immunotherapy with checkpoint inhibitors, such as PD-1 and PD-L1, has been largely unsuccessful in prostate cancer (Isaacsson Velho \& Antonarakis 2018). Interestingly, in melanoma and ovarian cancer models, EZH2 is negatively associated with tumour-infiltrating CD8+ T-cells; EZH2-mediated silencing of T-cell attractant chemokines as well as genes essential for antigen processing and presentation represses tumour immunogenicity and T-cell infiltration (Peng et al. 2015, Nagarsheth et al. 2016, Zingg et al. 2017). Accordingly, EZH2 inhibition can synergize with immune checkpoint inhibitors to augment the infiltration of CD8+ T-cells into the tumour microenvironment and improve tumour control (Zingg et al. 2017). This has important implications for prostate cancer as EZH2 inhibition may have utility in reversing the immunologically 'cold' nature of these tumours. Clinical trials of EZH2 inhibitors in combination with Ipilimumab (a monoclonal antibody that activates the immune system by targeting CTLA-4) in patients with advanced solid tumours are ongoing (NCT03525795).

Epigenetic drugs targeting the BET family of chromatin readers and transcriptional regulators, such as BRD4, are also in clinical development. Pre-clinical studies have shown that drugs targeting BRD4 disrupt its recruitment to chromatin sites bound by AR, suppress signaling, and, alone or in combination with ARPIs, demonstrate anti-tumour activity (Asangani et al. 2014, 2016, Welti et al. 2018). This is due, in part, to the requirement of BRD4 activity to mediate chromatin accessibility and AR transcriptional reprogramming during prostate cancer progression (Urbanucci et al. 2017). A phase I/II trial is ongoing to examine the effects of the BET inhibitor ZEN003694 in combination with enzalutamide in CRPC (NCT02711956). Likewise, LSD1-targeting drugs may also have utility in NEPC since LSD1 is highly expressed in the androgen-independent disease state, modulates FOXA1-dependent AR cistrome reprogramming, and activates stem cell-associated gene networks (Cai et al. 2014, Sehrawat et al. 2018). Together, these studies suggest that concerted blockade of the AR and epigenetic reprogramming factors might be an effective approach to prevent or delay NEPC; further biomarker-driven clinical trials in this space are warranted.

\section{Summary}

It is becoming increasingly clear that epigenetic and transcriptional dysregulation is central to the emergence and maintenance of highly aggressive and lethal NEPC tumours. Aberrant function of master epigenetic regulators, such as DNMT1 and EZH2, as well as pioneer transcription factors facilitate chromatin remodeling to support the activation of alternative lineage programs that, under potent androgen receptor antagonism, largely default to neuroendocrine differentiation. These epigenetic changes are fueled, in part, through metabolic reprogramming. The exquisite dependency of NEPC tumours on the epigenetic and transcriptional machinery provides an Achilles' heel that has already begun to be exploited therapeutically. These epigenetic therapies have shown promise clinically; however, numerous challenges remain with respect to patient stratification, timing, and combination with ARPIs and/or immunotherapy to refine the development of more precise, biomarker-driven treatment strategies for NEPC.

\section{Declaration of interest}

The authors declare that there is no conflict of interest that could be perceived as prejudicing the impartiality of this review.

\section{Funding}

This work was supported in part by funding from the National Health and Medical Research Council of Australia (ID 1121057 to L A S), the Canadian Institutes of Health Research (to A D and A Z), and the Prostate Cancer Foundation (to A D and A Z).

\section{Acknowledgements}

The authors acknowledge that many important studies relevant to this review are not cited herein and apologize for omissions due to limitations of both space and scope.

\section{References}

Abida W, Cyrta J, Heller G, Prandi D, Armenia J, Coleman I, Cieslik M, Benelli M, Robinson D, Van Allen EM, et al. 2019 Genomic correlates of clinical outcome in advanced prostate cancer. PNAS 116 11428-11436. (https://doi.org/10.1073/pnas.1902651116)

Adamo A, Sese B, Boue S, Castano J, Paramonov I, Barrero MJ \& Izpisua Belmonte JC 2011 LSD1 regulates the balance between self-renewal and differentiation in human embryonic stem cells. Nature Cell Biology 13 652-659. (https://doi.org/10.1038/ncb2246)

Adams EJ, Karthaus WR, Hoover E, Liu D, Gruet A, Zhang Z, Cho H, DiLoreto R, Chhangawala S, Liu Y, et al. 2019 FOXA1 mutations alter pioneering activity, differentiation and prostate cancer phenotypes. Nature 571 408-412. (https://doi.org/10.1038/s41586-019-1318-9)

Aggarwal RR, Youngren J, Sokolov A, Huang J, Thomas GV, True LD, Foye A, Alumkal JJ, Ryan CJ, Beer TM, et al. 2016 Persistence of AR signaling in small cell neuroendocrine prostate cancer (SCNC) and intermediate atypical carcinoma (IAC): results from the SU2C/PCF/ AACR West Coast Prostate Cancer Dream Team (WCDT). Journal of Clinical Oncology 34 5045-5045. (https://doi.org/10.1200/ JCO.2016.34.15_suppl.5045) 
Aggarwal R, Huang J, Alumkal JJ, Zhang L, Feng FY, Thomas GV, Weinstein AS, Friedl V, Zhang C, Witte ON, et al. 2018 Clinical and genomic characterization of treatment-emergent small-cell neuroendocrine prostate cancer: a multi-institutional prospective study. Journal of Clinical Oncology 36 2492-2503. (https://doi. org/10.1200/JCO.2017.77.6880)

Aparicio AM, Harzstark AL, Corn PG, Wen S, Araujo JC, Tu SM, Pagliaro LC, Kim J, Millikan RE, Ryan C, et al. 2013 Platinum-based chemotherapy for variant castrate-resistant prostate cancer. Clinical Cancer Research 19 3621-3630. (https://doi.org/10.1158/1078-0432. CCR-12-3791)

Asangani IA, Ateeq B, Cao Q, Dodson L, Pandhi M, Kunju LP, Mehra R, Lonigro RJ, Siddiqui J, Palanisamy N, et al. 2013 Characterization of the EZH2-MMSET histone methyltransferase regulatory axis in cancer. Molecular Cell 49 80-93. (https://doi.org/10.1016/j. molcel.2012.10.008)

Asangani IA, Dommeti VL, Wang X, Malik R, Cieslik M, Yang R, EscaraWilke J, Wilder-Romans K, Dhanireddy S, Engelke C, et al. 2014 Therapeutic targeting of BET bromodomain proteins in castrationresistant prostate cancer. Nature 510 278-282. (https://doi. org/10.1038/nature13229)

Asangani IA, Wilder-Romans K, Dommeti VL, Krishnamurthy PM, Apel IJ, Escara-Wilke J, Plymate SR, Navone NM, Wang S, Feng FY, et al. 2016 BET bromodomain inhibitors enhance efficacy and disrupt resistance to AR antagonists in the treatment of prostate cancer. Molecular Cancer Research 14 324-331. (https://doi. org/10.1158/1541-7786.MCR-15-0472)

Ather MH, Abbas F, Faruqui N, Israr M \& Pervez S 2008 Correlation of three immunohistochemically detected markers of neuroendocrine differentiation with clinical predictors of disease progression in prostate cancer. BMC Urology 8 21. (https://doi.org/10.1186/14712490-8-21)

Augert A, Eastwood E, Ibrahim AH, Wu N, Grunblatt E, Basom R, Liggitt D, Eaton KD, Martins R, Poirier JT, et al. 2019 Targeting NOTCH activation in small cell lung cancer through LSD1 inhibition. Science Signaling 12 eaau2922. (https://doi.org/10.1126/ scisignal.aau2922)

Aytes A, Giacobbe A, Mitrofanova A, Ruggero K, Cyrta J, Arriaga J, Palomero L, Farran-Matas S, Rubin MA, Shen MM, et al. 2018 NSD2 is a conserved driver of metastatic prostate cancer progression. Nature Communications 9 5201. (https://doi.org/10.1038/s41467-01807511-4)

Beltran H, Rickman DS, Park K, Chae SS, Sboner A, MacDonald TY, Wang Y, Sheikh KL, Terry S, Tagawa ST, et al. 2011 Molecular characterization of neuroendocrine prostate cancer and identification of new drug targets. Cancer Discovery 1 487-495. (https://doi. org/10.1158/2159-8290.CD-11-0130)

Beltran H, Prandi D, Mosquera JM, Benelli M, Puca L, Cyrta J, Marotz C, Giannopoulou E, Chakravarthi BV, Varambally S, et al. 2016 Divergent clonal evolution of castration-resistant neuroendocrine prostate cancer. Nature Medicine 22 298-305. (https://doi. org/10.1038/nm.4045)

Berger A, Brady NJ, Bareja R, Robinson B, Conteduca V, Augello MA, Puca L, Ahmed A, Dardenne E, Lu X, et al. 2019 N-Myc-mediated epigenetic reprogramming drives lineage plasticity in advanced prostate cancer. Journal of Clinical Investigation 130 3924-3940. (https://doi.org/10.1172/JCI127961)

Bhagirath D, Yang TL, Tabatabai ZL, Majid S, Dahiya R, Tanaka Y \& Saini S 2019 BRN4 is a novel driver of neuroendocrine differentiation in castration-resistant prostate cancer and is selectively released in extracellular vesicles with BRN2. Clinical Cancer Research 25 6532-6545. (https://doi.org/10.1158/1078-0432. CCR-19-0498)

Bishop JL, Thaper D, Vahid S, Davies A, Ketola K, Kuruma H, Jama R, Nip KM, Angeles A, Johnson F, et al. 2017 The master neural transcription factor BRN2 is an androgen receptor-suppressed driver of neuroendocrine differentiation in prostate cancer. Cancer Discovery 7 54-71. (https://doi.org/10.1158/2159-8290.CD-15-1263)

Bluemn EG, Coleman IM, Lucas JM, Coleman RT, Hernandez-Lopez S, Tharakan R, Bianchi-Frias D, Dumpit RF, Kaipainen A, Corella AN, et al. 2017 Androgen receptor pathway-independent prostate cancer is sustained through FGF signaling. Cancer Cell 32 474.e6-489.e6. (https://doi.org/10.1016/j.ccell.2017.09.003)

Cai C, He HH, Chen S, Coleman I, Wang H, Fang Z, Chen S, Nelson PS, Liu XS, Brown M, et al. 2011 Androgen receptor gene expression in prostate cancer is directly suppressed by the androgen receptor through recruitment of lysine-specific demethylase 1. Cancer Cell 20 457-471. (https://doi.org/10.1016/j.ccr.2011.09.001)

Cai H, Memarzadeh S, Stoyanova T, Beharry Z, Kraft AS \& Witte ON 2012 Collaboration of Kras and androgen receptor signaling stimulates EZH2 expression and tumor-propagating cells in prostate cancer. Cancer Research 72 4672-4681. (https://doi.org/10.1158/00085472.CAN-12-0228)

Cai C, He HH, Gao S, Chen S, Yu Z, Gao Y, Chen S, Chen MW, Zhang J, Ahmed M, et al. 2014 Lysine-specific demethylase 1 has dual functions as a major regulator of androgen receptor transcriptional activity. Cell Reports 9 1618-1627. (https://doi.org/10.1016/j. celrep.2014.11.008)

Chen T \& Dent SY 2014 Chromatin modifiers and remodellers: regulators of cellular differentiation. Nature Reviews: Genetics $\mathbf{1 5}$ 93-106. (https://doi.org/10.1038/nrg3607)

Chen L, Alexe G, Dharia NV, Ross L, Iniguez AB, Conway AS, Wang EJ, Veschi V, Lam N, Qi J, et al. 2018 CRISPR-Cas9 screen reveals a MYCN-amplified neuroblastoma dependency on EZH2. Journal of Clinical Investigation 128 446-462. (https://doi.org/10.1172/ JCI90793)

Choi YJ, Lin CP, Ho JJ, He X, Okada N, Bu P, Zhong Y, Kim SY, Bennett MJ, Chen C, et al. 2011 miR-34 miRNAs provide a barrier for somatic cell reprogramming. Nature Cell Biology 13 1353-1360. (https://doi.org/10.1038/ncb2366)

Choi SYC, Ettinger SL, Lin D, Xue H, Ci X, Nabavi N, Bell RH, Mo F, Gout PW, Fleshner NE, et al. 2018 Targeting MCT4 to reduce lactic acid secretion and glycolysis for treatment of neuroendocrine prostate cancer. Cancer Medicine 7 3385-3392. (https://doi. org/10.1002/cam4.1587)

Clermont PL, Lin D, Crea F, Wu R, Xue H, Wang Y, Thu KL, Lam WL, Collins CC, Wang Y, et al. 2015 Polycomb-mediated silencing in neuroendocrine prostate cancer. Clinical Epigenetics 7 40. (https://doi. org/10.1186/s13148-015-0074-4)

Crea F, Hurt EM, Mathews LA, Cabarcas SM, Sun L, Marquez VE, Danesi R \& Farrar WL 2011 Pharmacologic disruption of polycomb repressive complex 2 inhibits tumorigenicity and tumor progression in prostate cancer. Molecular Cancer 10 40. (https://doi. org/10.1186/1476-4598-10-40)

Dardenne E, Beltran H, Benelli M, Gayvert K, Berger A, Puca L, Cyrta J, Sboner A, Noorzad Z, MacDonald T, et al. 2016 N-Myc induces an EZH2-mediated transcriptional program driving neuroendocrine prostate cancer. Cancer Cell 30 563-577. (https://doi.org/10.1016/j. ccell.2016.09.005)

Das R, Gregory PA, Fernandes RC, Denis I, Wang Q, Townley SL, Zhao SG, Hanson AR, Pickering MA, Armstrong HK, et al. 2017 MicroRNA-194 promotes prostate cancer metastasis by inhibiting SOCS2. Cancer Research 77 1021-1034. (https://doi. org/10.1158/0008-5472.CAN-16-2529)

Davies AH, Beltran H \& Zoubeidi A 2018 Cellular plasticity and the neuroendocrine phenotype in prostate cancer. Nature Reviews: Urology 15 271-286. (https://doi.org/10.1038/nrurol.2018.22)

DeGraff DJ, Grabowska MM, Case TC, Yu X, Herrick MK, Hayward WJ, Strand DW, Cates JM, Hayward SW, Gao N, et al. 2014 FOXA1 deletion in luminal epithelium causes prostatic hyperplasia and alteration of differentiated phenotype. Laboratory Investigation 94 726-739. (https://doi.org/10.1038/labinvest.2014.64) (c) 2020 Society for Endocrinology Published by Bioscientifica Ltd. Printed in Great Britain 
Di Micco R, Fontanals-Cirera B, Low V, Ntziachristos P, Yuen SK, Lovell CD, Dolgalev I, Yonekubo Y, Zhang G, Rusinova E, et al. 2014 Control of embryonic stem cell identity by BRD4-dependent transcriptional elongation of super-enhancer-associated pluripotency genes. Cell Reports 9 234-247. (https://doi.org/10.1016/j. celrep.2014.08.055)

Du B \& Shim JS 2016 Targeting epithelial-mesenchymal transition (EMT) to overcome drug resistance in cancer. Molecules 21 E965. (https:// doi.org/10.3390/molecules21070965)

Esposito S, Russo MV, Airoldi I, Tupone MG, Sorrentino C, Barbarito G, Di Meo S \& Di Carlo E 2015 SNAI2/Slug gene is silenced in prostate cancer and regulates neuroendocrine differentiation, metastasissuppressor and pluripotency gene expression. Oncotarget 6 17121-17134. (https://doi.org/10.18632/oncotarget.2736)

Esteve PO, Chang Y, Samaranayake M, Upadhyay AK, Horton JR, Feehery GR, Cheng X \& Pradhan S 2011 A methylation and phosphorylation switch between an adjacent lysine and serine determines human DNMT1 stability. Nature Structural and Molecular Biology 18 42-48. (https://doi.org/10.1038/nsmb.1939)

Faivre EJ, Wilcox D, Lin X, Hessler P, Torrent M, He W, Uziel T, Albert DH, McDaniel K, Kati W, et al. 2017 Exploitation of castration-resistant prostate cancer transcription factor dependencies by the novel BET inhibitor ABBV-075. Molecular Cancer Research 15 35-44. (https://doi.org/10.1158/1541-7786.MCR-16-0221)

Feng J, Xu G, Liu J, Zhang N, Li L, Ji J, Zhang J, Zhang L, Wang G, Wang X, et al. 2016 Phosphorylation of LSD1 at Ser112 is crucial for its function in induction of EMT and metastasis in breast cancer. Breast Cancer Research and Treatment 159 443-456. (https://doi. org/10.1007/s10549-016-3959-9)

Flores-Morales A, Bergmann TB, Lavallee C, Batth TS, Lin D, Lerdrup M, Friis S, Bartels A, Kristensen G, Krzyzanowska A, et al. 2019 Proteogenomic characterization of patient-derived xenografts highlights the role of REST in neuroendocrine differentiation of castration-resistant prostate cancer. Clinical Cancer Research $\mathbf{2 5}$ 595-608. (https://doi.org/10.1158/1078-0432.CCR-18-0729)

Fu M, Liu M, Sauve AA, Jiao X, Zhang X, Wu X, Powell MJ, Yang T, $\mathrm{Gu}$ W, Avantaggiati ML, et al. 2006 Hormonal control of androgen receptor function through SIRT1. Molecular and Cellular Biology 26 8122-8135. (https://doi.org/10.1128/MCB.00289-06)

Gan Y, Li Y, Long Z, Lee AR, Xie N, Lovnicki JM, Tang Y, Chen X, Huang J \& Dong X 2018 Roles of alternative RNA splicing of the Bif-1 gene by SRRM4 during the development of treatment-induced neuroendocrine prostate cancer. EBioMedicine 31 267-275. (https:// doi.org/10.1016/j.ebiom.2018.05.002)

Gao N, Ishii K, Mirosevich J, Kuwajima S, Oppenheimer SR, Roberts RL, Jiang M, Yu X, Shappell SB, Caprioli RM, et al. 2005 Forkhead box A1 regulates prostate ductal morphogenesis and promotes epithelial cell maturation. Development 132 3431-3443. (https://doi. org/10.1242/dev.01917)

Gonzales-Cope M, Sidoli S, Bhanu NV, Won KJ \& Garcia BA 2016 Histone $\mathrm{H} 4$ acetylation and the epigenetic reader $\mathrm{Brd} 4$ are critical regulators of pluripotency in embryonic stem cells. BMC Genomics 17 95. (https://doi.org/10.1186/s12864-016-2414-y)

Gravina GL, Festuccia C, Millimaggi D, Dolo V, Tombolini V, de Vito M, Vicentini C \& Bologna M 2008 Chronic azacitidine treatment results in differentiating effects, sensitizes against bicalutamide in androgen-independent prostate cancer cells. Prostate 68 793-801. (https://doi.org/10.1002/pros.20748)

Gravina GL, Marampon F, Di Staso M, Bonfili P, Vitturini A, Jannini EA, Pestell RG, Tombolini V \& Festuccia C 2010 5-Azacitidine restores and amplifies the bicalutamide response on preclinical models of androgen receptor expressing or deficient prostate tumors. Prostate 70 1166-1178. (https://doi.org/10.1002/pros.21151)

Greenberg MVC \& Bourc'his D 2019 The diverse roles of DNA methylation in mammalian development and disease. Nature
Reviews: Molecular Cell Biology 20 590-607. (https://doi.org/10.1038/ s41580-019-0159-6)

Guo H, Ci X, Ahmed M, Hua JT, Soares F, Lin D, Puca L, Vosoughi A, Xue H, Li E, et al. 2019 ONECUT2 is a driver of neuroendocrine prostate cancer. Nature Communications 10 278. (https://doi. org/10.1038/s41467-018-08133-6)

Henssen A, Althoff K, Odersky A, Beckers A, Koche R, Speleman F, Schafers S, Bell E, Nortmeyer M, Westermann F, et al. 2016 Targeting MYCN-driven transcription by BET-bromodomain inhibition. Clinical Cancer Research 22 2470-2481. (https://doi.org/10.1158/1078-0432. CCR-15-1449)

Isaacsson Velho P \& Antonarakis ES 2018 PD-1/PD-L1 pathway inhibitors in advanced prostate cancer. Expert Review of Clinical Pharmacology 11 475-486. (https://doi.org/10.1080/17512433.2018.1 464388)

Jeter CR, Liu B, Lu Y, Chao HP, Zhang D, Liu X, Chen X, Li Q, Rycaj K, Calhoun-Davis T, et al. 2016 NANOG reprograms prostate cancer cells to castration resistance via dynamically repressing and engaging the AR/FOXA1 signaling axis. Cell Discovery 2 16041. (https://doi. org/10.1038/celldisc.2016.41)

Jia L, Berman BP, Jariwala U, Yan X, Cogan JP, Walters A, Chen T, Buchanan G, Frenkel B \& Coetzee GA 2008 Genomic androgen receptor-occupied regions with different functions, defined by histone acetylation, coregulators and transcriptional capacity. PLoS ONE 3 e3645. (https://doi.org/10.1371/journal.pone.0003645)

Jozwik KM \& Carroll JS 2012 Pioneer factors in hormone-dependent cancers. Nature Reviews: Cancer 12 381-385. (https://doi.org/10.1038/ nrc3263)

Kareta MS, Gorges LL, Hafeez S, Benayoun BA, Marro S, Zmoos AF, Cecchini MJ, Spacek D, Batista LF, O'Brien M, et al. 2015 Inhibition of pluripotency networks by the $\mathrm{Rb}$ tumor suppressor restricts reprogramming and tumorigenesis. Cell Stem Cell 16 39-50. (https:// doi.org/10.1016/j.stem.2014.10.019)

Kim E, Kim M, Woo DH, Shin Y, Shin J, Chang N, Oh YT, Kim H, Rheey J, Nakano I, et al. 2013 Phosphorylation of EZH2 activates STAT3 signaling via STAT3 methylation and promotes tumorigenicity of glioblastoma stem-like cells. Cancer Cell 23 839-852. (https://doi. $\operatorname{org} / 10.1016 /$ j.ccr.2013.04.008)

Kim KH, Kim W, Howard TP, Vazquez F, Tsherniak A, Wu JN, Wang W, Haswell JR, Walensky LD, Hahn WC, et al. 2015 SWI/SNF-mutant cancers depend on catalytic and non-catalytic activity of EZH2. Nature Medicine 21 1491-1496. (https://doi.org/10.1038/nm.3968)

Kim J, Jin H, Zhao JC, Yang YA, Li Y, Yang X, Dong X \& Yu J 2017 FOXA1 inhibits prostate cancer neuroendocrine differentiation. Oncogene 36 4072-4080. (https://doi.org/10.1038/onc.2017.50)

Kim J, Lee Y, Lu X, Song B, Fong KW, Cao Q, Licht JD, Zhao JC \& Yu J 2018 Polycomb- and methylation-independent roles of EZH2 as a transcription activator. Cell Reports 25 2808.e4-2820.e4. (https://doi. org/10.1016/j.celrep.2018.11.035)

Kleb B, Estecio MR, Zhang J, Tzelepi V, Chung W, Jelinek J, Navone NM, Tahir S, Marquez VE, Issa JP, et al. 2016 Differentially methylated genes and androgen receptor re-expression in small cell prostate carcinomas. Epigenetics 11 184-193. (https://doi.org/10.1080/155922 94.2016.1146851)

Knoepfler PS, Zhang XY, Cheng PF, Gafken PR, McMahon SB \& Eisenman RN 2006 Myc influences global chromatin structure. EMBO Journal 25 2723-2734. (https://doi.org/10.1038/sj. emboj.7601152)

Koochekpour S, Majumdar S, Azabdaftari G, Attwood K, Scioneaux R, Subramani D, Manhardt C, Lorusso GD, Willard SS, Thompson H, et al. 2012 Serum glutamate levels correlate with Gleason score and glutamate blockade decreases proliferation, migration, and invasion and induces apoptosis in prostate cancer cells. Clinical Cancer Research 18 5888-5901. (https://doi.org/10.1158/1078-0432.CCR-121308)
(C) 2020 Society for Endocrinology Published by Bioscientifica Ltd. Printed in Great Britain 
Ku SY, Rosario S, Wang Y, Mu P, Seshadri M, Goodrich ZW, Goodrich MM, Labbe DP, Gomez EC, Wang J, et al. 2017 Rb1 and Trp53 cooperate to suppress prostate cancer lineage plasticity, metastasis, and antiandrogen resistance. Science 355 78-83. (https:// doi.org/10.1126/science.aah4199)

Ku SY, Gleave ME \& Beltran H 2019 Towards precision oncology in advanced prostate cancer. Nature Reviews: Urology 16 645-654. (https://doi.org/10.1038/s41585-019-0237-8)

Lee TI, Jenner RG, Boyer LA, Guenther MG, Levine SS, Kumar RM, Chevalier B, Johnstone SE, Cole MF, Isono K, et al. 2006 Control of developmental regulators by Polycomb in human embryonic stem cells. Cell 125 301-313. (https://doi.org/10.1016/j.cell.2006.02.043)

Lee ST, Li Z, Wu Z, Aau M, Guan P, Karuturi RK, Liou YC \& Yu Q 2011 Context-specific regulation of NF-kappaB target gene expression by EZH2 in breast cancers. Molecular Cell 43 798-810. (https://doi. org/10.1016/j.molcel.2011.08.011)

Lee JK, Phillips JW, Smith BA, Park JW, Stoyanova T, McCaffrey EF, Baertsch R, Sokolov A, Meyerowitz JG, Mathis C, et al. 2016 N-Myc drives neuroendocrine prostate cancer initiated from human prostate epithelial cells. Cancer Cell 29 536-547. (https://doi.org/10.1016/j. ccell.2016.03.001)

Lee AR, Li Y, Xie N, Gleave ME, Cox ME, Collins CC \& Dong X 2017 Alternative RNA splicing of the MEAF6 gene facilitates neuroendocrine prostate cancer progression. Oncotarget $\mathbf{8}$ 27966-27975. (https://doi.org/10.18632/oncotarget.15854)

Lee AR, Gan Y, Tang Y \& Dong X 2018 A novel mechanism of SRRM4 in promoting neuroendocrine prostate cancer development via a pluripotency gene network. EBioMedicine 35 167-177. (https://doi. org/10.1016/j.ebiom.2018.08.011)

Lenhart R, Kirov S, Desilva H, Cao J, Lei M, Johnston K, Peterson R, Schweizer L, Purandare A, Ross-Macdonald P, et al. 2015 Sensitivity of small cell lung cancer to BET inhibition is mediated by regulation of ASCL1 gene expression. Molecular Cancer Therapeutics $\mathbf{1 4}$ 2167-2174. (https://doi.org/10.1158/1535-7163.MCT-15-0037)

Li W, Cohen A, Sun Y, Squires J, Braas D, Graeber TG, Du L, Li G, Li Z, $\mathrm{Xu} \mathrm{X}$, et al. 2016 The role of CD44 in glucose metabolism in prostatic small cell neuroendocrine carcinoma. Molecular Cancer Research 14 344-353. (https://doi.org/10.1158/1541-7786.MCR-15-0466)

Li Y, Donmez N, Sahinalp C, Xie N, Wang Y, Xue H, Mo F, Beltran H, Gleave M, Wang Y, et al. 2017 SRRM4 drives neuroendocrine transdifferentiation of prostate adenocarcinoma under androgen receptor pathway inhibition. European Urology 71 68-78. (https://doi. org/10.1016/j.eururo.2016.04.028)

Li Y, Xie N, Chen R, Lee AR, Lovnicki J, Morrison EA, Fazli L, Zhang Q, Musselman CA, Wang Y, et al. 2019 RNA splicing of the BHC80 gene contributes to neuroendocrine prostate cancer progression. European Urology 76 157-166. (https://doi.org/10.1016/j.eururo.2019.03.011)

Liang Y, Ahmed M, Guo H, Soares F, Hua JT, Gao S, Lu C, Poon C, Han W, Langstein J, et al. 2017 LSD1-mediated epigenetic reprogramming drives CENPE expression and prostate cancer progression. Cancer Research 77 5479-5490. (https://doi. org/10.1158/0008-5472.CAN-17-0496)

Lin RK, Wu CY, Chang JW, Juan LJ, Hsu HS, Chen CY, Lu YY, Tang YA, Yang YC, Yang PC, et al. 2010 Dysregulation of p53/Sp1 control leads to DNA methyltransferase-1 overexpression in lung cancer. Cancer Research 70 5807-5817. (https://doi.org/10.1158/0008-5472. CAN-09-4161)

Lin D, Wyatt AW, Xue H, Wang Y, Dong X, Haegert A, Wu R, Brahmbhatt S, Mo F, Jong L, et al. 2014 High fidelity patient-derived xenografts for accelerating prostate cancer discovery and drug development. Cancer Research 74 1272-1283. (https://doi. org/10.1158/0008-5472.CAN-13-2921-T)

Lin J, Patel SA, Sama AR, Hoffman-Censits JH, Kennedy B, Kilpatrick D, Ye Z, Yang H, Mu Z, Leiby B, et al. 2016a A Phase I/II study of the investigational drug alisertib in combination with abiraterone and prednisone for patients with metastatic castration-resistant prostate cancer progressing on abiraterone. Oncologist 21 1296e-1297e. (https://doi.org/10.1634/theoncologist.2016-0297)

Lin TP, Chang YT, Lee SY, Campbell M, Wang TC, Shen SH, Chung HJ, Chang YH, Chiu AW, Pan CC, et al. 2016b REST reduction is essential for hypoxia-induced neuroendocrine differentiation of prostate cancer cells by activating autophagy signaling. Oncotarget 7 26137-26151. (https://doi.org/10.18632/oncotarget.8433)

Liu X, Li C, Zhang R, Xiao W, Niu X, Ye X, Li Z, Guo Y, Tan J \& Li Y 2018 The EZH2-H3K27me3-DNMT1 complex orchestrates epigenetic silencing of the wwc1 gene, a Hippo/YAP pathway upstream effector, in breast cancer epithelial cells. Cellular Signalling 51 243-256. (https://doi.org/10.1016/j.cellsig.2018.08.011)

Maina PK, Shao P, Liu Q, Fazli L, Tyler S, Nasir M, Dong X \& Qi HH 2016 c-MYC drives histone demethylase PHF8 during neuroendocrine differentiation and in castration-resistant prostate cancer. Oncotarget 7 75585-75602. (https://doi.org/10.18632/ oncotarget.12310)

Maina PK, Shao P, Jia X, Liu Q, Umesalma S, Marin M, Long Jr D, Concepcion-Roman S \& Qi HH 2017 Histone demethylase PHF8 regulates hypoxia signaling through HIF1alpha and H3K4me3. Biochimica et Biophysica Acta: Gene Regulatory Mechanisms 1860 1002-1012. (https://doi.org/10.1016/j.bbagrm.2017.07.005)

McCabe MT, Davis JN \& Day ML 2005 Regulation of DNA methyltransferase 1 by the pRb/E2F1 pathway. Cancer Research $\mathbf{6 5}$ 3624-3632. (https://doi.org/10.1158/0008-5472.CAN-04-2158)

McKeithen D, Graham T, Chung LW \& Odero-Marah V 2010 Snail transcription factor regulates neuroendocrine differentiation in LNCaP prostate cancer cells. Prostate 70 982-992. (https://doi. org/10.1002/pros.21132)

Meder L, Konig K, Ozretic L, Schultheis AM, Ueckeroth F, Ade CP, Albus K, Boehm D, Rommerscheidt-Fuss U, Florin A, et al. 2016 NOTCH, ASCL1, p53 and RB alterations define an alternative pathway driving neuroendocrine and small cell lung carcinomas. International Journal of Cancer 138 927-938. (https://doi.org/10.1002/ ijc.29835)

Mirosevich J, Gao N, Gupta A, Shappell SB, Jove R \& Matusik RJ 2006 Expression and role of Foxa proteins in prostate cancer. Prostate 66 1013-1028. (https://doi.org/10.1002/pros.20299)

Mishra R, Haldar S, Placencio V, Madhav A, Rohena-Rivera K, Agarwal P, Duong F, Angara B, Tripathi M, Liu Z, et al. 2018 Stromal epigenetic alterations drive metabolic and neuroendocrine prostate cancer reprogramming. Journal of Clinical Investigation 128 4472-4484. (https://doi.org/10.1172/JCI99397)

Mu P, Zhang Z, Benelli M, Karthaus WR, Hoover E, Chen CC, Wongvipat J, Ku SY, Gao D, Cao Z, et al. 2017 SOX2 promotes lineage plasticity and antiandrogen resistance in TP53- and RB1deficient prostate cancer. Science 355 84-88. (https://doi.org/10.1126/ science.aah4307)

Nagarsheth N, Peng D, Kryczek I, Wu K, Li W, Zhao E, Zhao L, Wei S, Frankel T, Vatan L, et al. 2016 PRC2 epigenetically silences Th1-type chemokines to suppress effector T-cell trafficking in colon cancer. Cancer Research 76 275-282. (https://doi.org/10.1158/0008-5472. CAN-15-1938)

Nam RK, Benatar T, Amemiya Y, Wallis CJD, Romero JM, Tsagaris M, Sherman C, Sugar L \& Seth A 2018 MicroRNA-652 induces NED in LNCaP and EMT in PC3 prostate cancer cells. Oncotarget 9 19159-19176. (https://doi.org/10.18632/oncotarget.24937)

Nieto MA 2013 Epithelial plasticity: a common theme in embryonic and cancer cells. Science 342 1234850. (https://doi.org/10.1126/ science.1234850)

Nolan KD, Franco OE, Hance MW, Hayward SW \& Isaacs JS 2015 Tumor-secreted Hsp90 subverts polycomb function to drive prostate tumor growth and invasion. Journal of Biological Chemistry 290 8271-8282. (https://doi.org/10.1074/jbc.M115.637496)

Papadimitriou JC, Weihing RR, Choi C \& Drachenberg CB 1994 Prostatic marker-negative amphicrine carcinoma of the prostate. https://erc.bioscientifica.com

https://doi.org/10.1530/ERC-19-0420 (c) 2020 Society for Endocrinology Published by Bioscientifica Ltd. Printed in Great Britain 
Ultrastructural Pathology 18 357-363. (https://doi. org/10.3109/01913129409023204)

Paranjape AN, Soundararajan R, Werden SJ, Joseph R, Taube JH, Liu H, Rodriguez-Canales J, Sphyris N, Wistuba I, Miura N, et al. 2016 Inhibition of FOXC2 restores epithelial phenotype and drug sensitivity in prostate cancer cells with stem-cell properties. Oncogene 35 5963-5976. (https://doi.org/10.1038/onc.2015.498)

Park JW, Lee JK, Witte ON \& Huang J 2017 FOXA2 is a sensitive and specific marker for small cell neuroendocrine carcinoma of the prostate. Modern Pathology 30 1262-1272. (https://doi.org/10.1038/ modpathol.2017.44)

Park JW, Lee JK, Sheu KM, Wang L, Balanis NG, Nguyen K, Smith BA, Cheng C, Tsai BL, Cheng D, et al. 2018 Reprogramming normal human epithelial tissues to a common, lethal neuroendocrine cancer lineage. Science 362 91-95. (https://doi.org/10.1126/science.aat5749)

Parolia A, Cieslik M, Chu SC, Xiao L, Ouchi T, Zhang Y, Wang X, Vats P, Cao X, Pitchiaya S, et al. 2019 Distinct structural classes of activating FOXA1 alterations in advanced prostate cancer. Nature 571 413-418. (https://doi.org/10.1038/s41586-019-1347-4)

Peng D, Kryczek I, Nagarsheth N, Zhao L, Wei S, Wang W, Sun Y, Zhao E, Vatan L, Szeliga W, et al. 2015 Epigenetic silencing of TH1type chemokines shapes tumour immunity and immunotherapy. Nature 527 249-253. (https://doi.org/10.1038/nature15520)

Pomerantz MM, Li F, Takeda DY, Lenci R, Chonkar A, Chabot M, Cejas P, Vazquez F, Cook J, Shivdasani RA, et al. 2015 The androgen receptor cistrome is extensively reprogrammed in human prostate tumorigenesis. Nature Genetics 47 1346-1351. (https://doi. org/10.1038/ng.3419)

Popovic R, Martinez-Garcia E, Giannopoulou EG, Zhang Q, Zhang Q, Ezponda T, Shah MY, Zheng Y, Will CM, Small EC, et al. 2014 Histone methyltransferase MMSET/NSD2 alters EZH2 binding and reprograms the myeloma epigenome through global and focal changes in H3K36 and H3K27 methylation. PLoS Genetics 10 e1004566. (https://doi.org/10.1371/journal.pgen.1004566)

Puca L, Bareja R, Prandi D, Shaw R, Benelli M, Karthaus WR, Hess J, Sigouros M, Donoghue A, Kossai M, et al. 2018 Patient derived organoids to model rare prostate cancer phenotypes. Nature Communications 9 2404. (https://doi.org/10.1038/s41467-01804495-z)

Puissant A, Frumm SM, Alexe G, Bassil CF, Qi J, Chanthery YH, Nekritz EA, Zeid R, Gustafson WC, Greninger P, et al. 2013 Targeting MYCN in neuroblastoma by BET bromodomain inhibition. Cancer Discovery 3 308-323. (https://doi.org/10.1158/2159-8290.CD-12-0418)

Qi J, Nakayama K, Cardiff RD, Borowsky AD, Kaul K, Williams R, Krajewski S, Mercola D, Carpenter PM, Bowtell D, et al. 2010 Siah2dependent concerted activity of HIF and FoxA2 regulates formation of neuroendocrine phenotype and neuroendocrine prostate tumors. Cancer Cell 18 23-38. (https://doi.org/10.1016/j.ccr.2010.05.024)

Rapa I, Ceppi P, Bollito E, Rosas R, Cappia S, Bacillo E, Porpiglia F, Berruti A, Papotti M \& Volante M 2008 Human ASH1 expression in prostate cancer with neuroendocrine differentiation. Modern Pathology 21 700-707. (https://doi.org/10.1038/modpathol.2008.39)

Rapa I, Volante M, Migliore C, Farsetti A, Berruti A, Vittorio Scagliotti G, Giordano S \& Papotti M 2013 Human ASH-1 promotes neuroendocrine differentiation in androgen deprivation conditions and interferes with androgen responsiveness in prostate cancer cells. Prostate 73 1241-1249. (https://doi.org/10.1002/pros.22679)

Reina-Campos M, Linares JF, Duran A, Cordes T, L'Hermitte A, Badur MG, Bhangoo MS, Thorson PK, Richards A, Rooslid T, et al. 2019 Increased serine and one-carbon pathway metabolism by PKClambda/iota deficiency promotes neuroendocrine prostate cancer. Cancer Cell 35 385.e9-400.e9. (https://doi.org/10.1016/j. ccell.2019.01.018)

Rotinen M, You S, Yang J, Coetzee SG, Reis-Sobreiro M, Huang WC, Huang F, Pan X, Yanez A, Hazelett DJ, et al. 2018 ONECUT2 is a targetable master regulator of lethal prostate cancer that suppresses the androgen axis. Nature Medicine 24 1887-1898. (https://doi. org/10.1038/s41591-018-0241-1)

Ruan L, Wang L, Wang X, He M \& Yao X 2018 SIRT1 contributes to neuroendocrine differentiation of prostate cancer. Oncotarget 9 2002-2016. (https://doi.org/10.18632/oncotarget.23111)

Ryu S, McDonnell K, Choi H, Gao D, Hahn M, Joshi N, Park SM, Catena R, Do Y, Brazin J, et al. 2013 Suppression of miRNA-708 by polycomb group promotes metastases by calcium-induced cell migration. Cancer Cell 23 63-76. (https://doi.org/10.1016/j. ccr.2012.11.019)

Saini S, Majid S, Shahryari V, Arora S, Yamamura S, Chang I, Zaman MS, Deng G, Tanaka Y \& Dahiya R 2012 miRNA-708 control of CD44(+) prostate cancer-initiating cells. Cancer Research 72 3618-3630. (https://doi.org/10.1158/0008-5472.CAN-12-0540)

Schlesinger Y, Straussman R, Keshet I, Farkash S, Hecht M, Zimmerman J, Eden E, Yakhini Z, Ben-Shushan E, Reubinoff BE, et al. 2007 Polycomb-mediated methylation on Lys 27 of histone H3 pre-marks genes for de novo methylation in cancer. Nature Genetics 39 232-236. (https://doi.org/10.1038/ng1950)

Schvartzman JM, Thompson CB \& Finley LWS 2018 Metabolic regulation of chromatin modifications and gene expression. Journal of Cell Biology 217 2247-2259. (https://doi.org/10.1083/ jcb.201803061)

Sehrawat A, Gao L, Wang Y, Bankhead 3rd A, McWeeney SK, King CJ, Schwartzman J, Urrutia J, Bisson WH, Coleman DJ, et al. 2018 LSD1 activates a lethal prostate cancer gene network independently of its demethylase function. PNAS 115 E4179-E4188. (https://doi. org/10.1073/pnas.1719168115)

Shamma A, Suzuki M, Hayashi N, Kobayashi M, Sasaki N, Nishiuchi T, Doki Y, Okamoto T, Kohno S, Muranaka H, et al. 2013 ATM mediates pRB function to control DNMT1 protein stability and DNA methylation. Molecular and Cellular Biology 33 3113-3124. (https:// doi.org/10.1128/MCB.01597-12)

Shan J, Al-Muftah MA, Al-Kowari MK, Abuaqel SWJ, Al-Rumaihi K, Al-Bozom I, Li P \& Chouchane L 2019 Targeting Wnt/EZH2/ microRNA-708 signaling pathway inhibits neuroendocrine differentiation in prostate cancer. Cell Death Discovery 5139. (https://doi.org/10.1038/s41420-019-0218-y)

Smith BA, Sokolov A, Uzunangelov V, Baertsch R, Newton Y, Graim K, Mathis C, Cheng D, Stuart JM \& Witte ON 2015 A basal stem cell signature identifies aggressive prostate cancer phenotypes. PNAS 112 E6544-E6552. (https://doi.org/10.1073/pnas.1518007112)

Smith BA, Balanis NG, Nanjundiah A, Sheu KM, Tsai BL, Zhang Q, Park JW, Thompson M, Huang J, Witte ON, et al. 2018 A human adult stem cell signature marks aggressive variants across epithelial cancers. Cell Reports 24 3353.e5-3366.e5. (https://doi.org/10.1016/j. celrep.2018.08.062)

Sonpavde G, Aparicio AM, Zhan F, North B, Delaune R, Garbo LE, Rousey SR, Weinstein RE, Xiao L, Boehm KA, et al. 2011 Azacitidine favorably modulates PSA kinetics correlating with plasma DNA LINE-1 hypomethylation in men with chemonaive castrationresistant prostate cancer. Urologic Oncology 29 682-689. (https://doi. org/10.1016/j.urolonc.2009.09.015)

Sowalsky AG, Ye H, Bhasin M, Van Allen EM, Loda M, Lis RT, MontaserKouhsari L, Calagua C, Ma F, Russo JW, et al. 2018 Neoadjuvantintensive androgen deprivation therapy selects for prostate tumor foci with diverse subclonal oncogenic alterations. Cancer Research $\mathbf{7 8}$ 4716-4730. (https://doi.org/10.1158/0008-5472.CAN-18-0610)

Takahashi K \& Yamanaka S 2016 A decade of transcription factormediated reprogramming to pluripotency. Nature Reviews: Molecular Cell Biology 17 183-193. (https://doi.org/10.1038/nrm.2016.8)

Thibault A, Figg WD, Bergan RC, Lush RM, Myers CE, Tompkins A, Reed E \& Samid D 1998 A phase II study of 5-aza-2'deoxycytidine (decitabine) in hormone independent metastatic (D2) prostate cancer. Tumori 84 87-89. (https://doi. org/10.1177/030089169808400120) (c) 2020 Society for Endocrinology Published by Bioscientifica Ltd. Printed in Great Britain 
Tsai MC, Manor O, Wan Y, Mosammaparast N, Wang JK, Lan F, Shi Y, Segal E \& Chang HY 2010 Long noncoding RNA as modular scaffold of histone modification complexes. Science 329 689-693. (https:// doi.org/10.1126/science.1192002)

Tzelepi V, Zhang J, Lu JF, Kleb B, Wu G, Wan X, Hoang A, Efstathiou E, Sircar K, Navone NM, et al. 2012 Modeling a lethal prostate cancer variant with small-cell carcinoma features. Clinical Cancer Research 18 666-677. (https://doi.org/10.1158/1078-0432.CCR-11-1867)

Urbanucci A, Barfeld SJ, Kytola V, Itkonen HM, Coleman IM, Vodak D, Sjoblom L, Sheng X, Tolonen T, Minner S, et al. 2017 Androgen receptor deregulation drives bromodomain-mediated chromatin alterations in prostate cancer. Cell Reports 19 2045-2059. (https:// doi.org/10.1016/j.celrep.2017.05.049)

Varambally S, Dhanasekaran SM, Zhou M, Barrette TR, KumarSinha C, Sanda MG, Ghosh D, Pienta KJ, Sewalt RG, Otte AP, et al. 2002 The polycomb group protein EZH2 is involved in progression of prostate cancer. Nature $\mathbf{4 1 9}$ 624-629. (https://doi.org/10.1038/ nature01075)

Varlakhanova NV, Cotterman RF, deVries WN, Morgan J, Donahue LR, Murray S, Knowles BB \& Knoepfler PS 2010 Myc maintains embryonic stem cell pluripotency and self-renewal. Differentiation: Research in Biological Diversity 80 9-19. (https://doi.org/10.1016/j. diff.2010.05.001)

Vierbuchen T, Ostermeier A, Pang ZP, Kokubu Y, Sudhof TC \& Wernig M 2010 Direct conversion of fibroblasts to functional neurons by defined factors. Nature 463 1035-1041. (https://doi.org/10.1038/ nature08797)

Vire E, Brenner C, Deplus R, Blanchon L, Fraga M, Didelot C, Morey L, Van Eynde A, Bernard D, Vanderwinden JM, et al. 2006 The polycomb group protein EZH2 directly controls DNA methylation. Nature 439 871-874. (https://doi.org/10.1038/nature04431)

Viswanathan VS, Ryan MJ, Dhruv HD, Gill S, Eichhoff OM, SeashoreLudlow B, Kaffenberger SD, Eaton JK, Shimada K, Aguirre AJ, et al. 2017 Dependency of a therapy-resistant state of cancer cells on a lipid peroxidase pathway. Nature $\mathbf{5 4 7}$ 453-457. (https://doi. org/10.1038/nature23007)

Wan L, Xu K, Wei Y, Zhang J, Han T, Fry C, Zhang Z, Wang YV, Huang L, Yuan M, et al. 2018 Phosphorylation of EZH2 by AMPK suppresses PRC2 methyltransferase activity and oncogenic function. Molecular Cell 69 279.e5-291.e5. (https://doi.org/10.1016/j. molcel.2017.12.024)

Wang J, Hevi S, Kurash JK, Lei H, Gay F, Bajko J, Su H, Sun W, Chang H, $\mathrm{Xu} \mathrm{G}$, et al. 2009a The lysine demethylase LSD1 (KDM1) is required for maintenance of global DNA methylation. Nature Genetics $\mathbf{4 1}$ 125-129. (https://doi.org/10.1038/ng.268)

Wang Q, Li W, Zhang Y, Yuan X, Xu K, Yu J, Chen Z, Beroukhim R, Wang $\mathrm{H}$, Lupien $\mathrm{M}$, et al. 2009b Androgen receptor regulates a distinct transcription program in androgen-independent prostate cancer. Cell 138 245-256. (https://doi.org/10.1016/j.cell.2009.04.056)

Wang HJ, Pochampalli M, Wang LY, Zou JX, Li PS, Hsu SC, Wang BJ, Huang SH, Yang P, Yang JC, et al. 2019 KDM8/JMJD5 as a dual coactivator of AR and PKM2 integrates AR/EZH2 network and tumor metabolism in CRPC. Oncogene 38 17-32. (https://doi.org/10.1038/ s41388-018-0414-x)

Welti J, Sharp A, Yuan W, Dolling D, Nava Rodrigues D, Figueiredo I, Gil V, Neeb A, Clarke M, Seed G, et al. 2018 Targeting bromodomain and extra-terminal (BET) family proteins in castration-resistant prostate cancer (CRPC). Clinical Cancer Research 24 3149-3162. (https://doi.org/10.1158/1078-0432.CCR-17-3571)

Xiang S, Zou P, Tang Q, Zheng F, Wu J, Chen Z \& Hann SS 2018 HOTAIR-mediated reciprocal regulation of EZH2 and DNMT1 contribute to polyphyllin I-inhibited growth of castration-resistant prostate cancer cells in vitro and in vivo. Biochimica et Biophysica Acta: General Subjects 1862 589-599. (https://doi.org/10.1016/j. bbagen.2017.12.001)

Xu K, Wu ZJ, Groner AC, He HH, Cai C, Lis RT, Wu X, Stack EC, Loda M, Liu T, et al. $2012 \mathrm{EZH} 2$ oncogenic activity in castrationresistant prostate cancer cells is Polycomb-independent. Science 338 1465-1469. (https://doi.org/10.1126/science.1227604)

Yang M \& Vousden KH 2016 Serine and one-carbon metabolism in cancer. Nature Reviews: Cancer 16 650-662. (https://doi.org/10.1038/ nrc.2016.81)

Yang X, Chen MW, Terry S, Vacherot F, Chopin DK, Bemis DL, Kitajewski J, Benson MC, Guo Y \& Buttyan R 2005 A human- and male-specific protocadherin that acts through the Wnt signaling pathway to induce neuroendocrine transdifferentiation of prostate cancer cells. Cancer Research 65 5263-5271. (https://doi. org/10.1158/0008-5472.CAN-05-0162)

Zhang X, Coleman IM, Brown LG, True LD, Kollath L, Lucas JM, Lam HM, Dumpit R, Corey E, Chery L, et al. 2015 SRRM4 expression and the loss of REST activity may promote the emergence of the neuroendocrine phenotype in castration-resistant prostate cancer. Clinical Cancer Research 21 4698-4708. (https://doi. org/10.1158/1078-0432.CCR-15-0157)

Zhang Y, Zheng D, Zhou T, Song H, Hulsurkar M, Su N, Liu Y, Wang Z, Shao L, Ittmann M, et al. 2018 Androgen deprivation promotes neuroendocrine differentiation and angiogenesis through CREBEZH2-TSP1 pathway in prostate cancers. Nature Communications 9 4080. (https://doi.org/10.1038/s41467-018-06177-2)

Zheng Y, Sweet SM, Popovic R, Martinez-Garcia E, Tipton JD, Thomas PM, Licht JD \& Kelleher NL 2012 Total kinetic analysis reveals how combinatorial methylation patterns are established on lysines 27 and 36 of histone H3. PNAS 109 13549-13554. (https:// doi.org/10.1073/pnas.1205707109)

Zingg D, Arenas-Ramirez N, Sahin D, Rosalia RA, Antunes AT, Haeusel J, Sommer L \& Boyman O 2017 The histone methyltransferase Ezh2 controls mechanisms of adaptive resistance to tumor immunotherapy. Cell Reports 20 854-867. (https://doi.org/10.1016/j. celrep.2017.07.007)

Zou M, Toivanen R, Mitrofanova A, Floch N, Hayati S, Sun Y, Le Magnen C, Chester D, Mostaghel EA, Califano A, et al. 2017 Transdifferentiation as a mechanism of treatment resistance in a mouse model of castration-resistant prostate cancer. Cancer Discovery 7 736-749. (https://doi.org/10.1158/2159-8290.CD-16-1174)

Received in final form 28 November 2019

Accepted 4 December 2019

Accepted Manuscript published online 5 December 2019 https://erc.bioscientifica.com

https://doi.org/10.1530/ERC-19-0420 (c) 2020 Society for Endocrinology Published by Bioscientifica Ltd. Printed in Great Britain 